\title{
Problems in catfish anatomy and phylogeny exemplified by the Neotropical Hypophthalmidae (Teleostei: Siluroidei)
}

\section{Gordon J. Howes}

Department of Zoology, British Museum (Natural History), Cromwell Road, London SW7 5BD

\section{Contents}

Introduction

List of genera examined

Form and function in Hypophthalmus and comparison with other siluroids

Body shape, sensory canals and lateral line system

The eye and infraorbital bones

Cranial musculature

The snout and jaws

The cranium

The complex vertebrae, swimbladder and posterior lateral line nerve .

The suspensorium

The hyoid arch

The opercular series

The gill arches

Postcranial elements

Relationships of the Hypophthalmidae

Acknowledgements

References

\section{Introduction}

Of the subgroups of otophysan fishes, the siluroids-or catfishes-are the most morphologically diverse. None of the other subgroups, gymnotoids, characoids and cyprinoids, has such a range of body shape, peculiarity of dermal covering when present, and cranial morphology. Neither do these groups display such a range of postcranial architecture, complex fusion patterns of the caudal fin skeleton or such diverse forms of swimbladder. This morphological diversity is reflected in the most recent familial classification of the siluroids (Greenwood et al., 1966), which recognises thirty-one families, a number exceeding the combined familial total of other otophysan groups.

As presently recognised, most siluroid families are morphologically well differentiated, suggesting that each is probably a monophyletic assemblage. Indeed, the large morphological 'gaps' separating families are emphasised by the fact that seven families are monotypic, cf one among characoids and two among gymnotoids. That the interrelationships of siluroid families have scarcely been studied is not surprising when one considers the paucity of anatomical data available. Even the largest families, i.e. the Pimelodidae, Ariidae and Bagridae are represented in the anatomical literature by only meagre information, the anatomy of some neotropical families, Auchenipteridae, Ageneiosidae, and Aspredinidae, has scarcely been described.

The siluroids offer a wealth of character complexes involving the bony elements of the cranium, vertebral column and fin supports, and their associated muscles. These character 
complexes lend themselves readily to the application of cladistic methodology. The task of analysis is, however, a daunting one. Not only is the number of taxa considerable, over 2000 species, but, by their very nature, siluroids are difficult to study. Most adult specimens are large and highly ossified, and sutures between bones are often obscured in dry skeletal material. It is therefore necessary to work, for the most part, with cleared and stained preparations of small, and frequently juvenile specimens. Thus problems can arise in the interpretation of features which undergo considerable ontogenetic change.

One of the generalisations made about siluroids is that they are benthic fishes. In fact, the majority of species in seven families, Siluridae, Schilbeidae, Pangasiidae, Ariidae, Ageneiosidae, Cetopsidae, Hypophthalmidae, are mid-water to surface dwellers, and only in one third of families, Loricariidae, Amphiliidae, Callichthyidae, Astroblepidae, Doradidae, Chacidae, Sisoridae, Cranoglanididae, can the majority of included taxa be classed as entirely benthic. In the past more attention has been given to siluroid inter- than to intrarelationships. The most recent analysis (Fink \& Fink, 1981) recognises the siluroids as a suborder, the Siluroidei, coordinate with their supposed sister group, the Gymnotoidei which together form the order Siluriformes. The Siluriformes are, in turn, thought to be the sister group of the characoids, order Characiformes, with the cyprinoids, order Cypriniformes, representing the plesiomorph lineage and sister group of the Silurifomes + the Characiformes.

Only the most rudimentary analyses have been attempted on the functional anatomy of siluroids (Eaton, 1948; Alexander, 1965; Gosline, 1973 \& 1975). According to Gosline (1973) siluroids employ a feeding mechanism functionally different from that of other otophysans. But again, lack of comparative anatomical data prohibits any worthwhile discussion of this issue.

One attempt at cladistic analysis involving several siluroid families has been published by Lundberg \& Baskin (1969). In order to obtain an understanding of siluroid relationships these authors chose to focus efforts '. . . on comparative studies of a single structural complex in obtaining an understanding of siluroid relationships'. This approach, whilst accumulating valuable comparative data, can however, produce a misleading phylogeny. The weakness inherent in an approach that places reliance on single character complexes is discussed below (p. 27) with reference to patterns of vertebral fusion and swimbladder encapsulation.

Roberts (1973) notes that the '... cosmopolitan distribution of siluroids and their pseudarchaic characters have led ichthyologists to believe catfishes to be older than other ostariophysans'. I presume 'pseudarchaic' as used by Roberts means 'neomorph' resulting in convergences with features found in ancient groups. But, neomorphs are no indication of the group's phyletic age. On the other hand, the cosmopolitan distribution of siluroids may suggest an early and extensive distribution whereas the more restricted distribution of other otophysans could indicate their later cladogenesis from the ancestral otophysan lineage.

The subject of this paper, the family Hypophthalmidae, is chosen for anatomical investigation because it represents several aspects of the problems discussed above. The family is monotypic, apparently 'isolated' phyletically, is 'pelagic' in habits, and poses intriguing problems of functional anatomy. The object of the study is to describe the osteological and myological features, with particular regard to the cranium, to analyse these features in terms of their apo-plesiomorphic status, to account for their functional relevance, and to use these data as indicators of phyletic relationship.

Günther (1864:3:66) first recognised the distinctiveness of Hypophthalmus by placing it in a separate subfamily, Siluroidae Anomalopterae (Group Hypophthalmina). Helogenes was also included on the basis of its elongate anal fin, and its short dorsal and adipose fins. Cope (1871) established the Hypophthalmidae as one of three families of his Nematognathi. In Cope's view Hypophthalmus was so aberrant that he doubted its relationships with other catfishes. Eigenmann \& Eigenmann (1890) continued to recognise Günther's concept of the family but Regan (1911) placed Helogenes in a separate family thereby establishing the Hypophthalmidae as monotypic. Chardon (1968) chose to recognise the uniqueness of the 
Hypophthalmidae by placing it in its own suborder, the Hypophthalmoidei. He was, however, unable to relate the taxon closely with another of equal rank.

As yet, the taxonomy of the genus Hypophthalmus has received no thorough treatment. Eigenmann \& Eigenmann (1890) synonymised the six nominate species with $H$. edentatus, the type of the genus, stating 'There is little doubt but that the species have been based on the different stages of one species'. More recently, however, Roberts (1972:139) noted there are '....three very distinct species of Hypophthalmus in the Amazon'. In the most recent literature authors have recognised a second species named as $H$. perporosus Cope, 1878 (see Goulding, 1980; Carvalho, 1980a).

Although Hypophthalmus is a common commercial food fish in Amazonia (see Roberts, 1972: 140), its ecology is poorly studied (for accounts see Roberts, 1972; Meschkat, 1960; Goulding, 1980; Carvalho, 1980a \& b). Hypophthalmus species are shoalers and filter-feed, chiefly on zooplankton. According to Carvalho (1980b), the larger proportion of ingested food of $H$. edentatus comprises cladocerans and copepods. Gut contents of specimens personally examined contain insect (Hymenoptera) leg and antennal fragments, and fragmented plant material (portions of leaves, stems, pollen cuticles and seed spikes). Carvalho (1980b) classifies Hypophthalmus as a pelagic zooplanktivore but perhaps, in view of the above catalogue of gut contents, it should more rightly be classed as a detrital filterfeeder. As in other detritivores, Hypophthalmus has a long, convoluted gut.

Only two papers deal with any detailed aspect of hypophthalmine anatomy. Wright (1885) described the skull and swimbladder connections. This paper, however, omits some important features and misinterprets others, omissions obviously due to limitations imposed by the use of dry skeletal material in which many delicate structures are lost or obliterated. Chardon (1968) also described the swimbladder and Weberian structure. His account and illustrations supplement those of Wright's. Roberts (1972) gives a more general account of Hypophthalmus, and includes a fairly detailed description of the gill arch structure and its likely mode of function.

\section{List of genera examined}

Where availability of material has permitted, the cranial anatomy of at least two species in each polytypic genus has been examined.

$\mathrm{A}=$ alizarin stained specimen, $\mathrm{D}=$ dry skeleton, $\mathrm{S}=$ alcohol preserved specimens (dissected).

Aelurichthys D

Ageniosus A, D, S

Amphilius A

Arius A, D, S

Aspredo $\mathrm{S}$

Auchenipterus A, D, S

Bagrus A, D, S

Brachyplatystoma $\mathrm{S}$

Branchioica A

Bunocephalus A

Callophysus S

Chaca D

Chaetostoma D

Chrysichthys A, D, S

Clarias A, D, S

Clarotes D, S

Cochliodon A

Cryptopterus D, S

Diplomystes D, S
Doras D

Eutropius D, S

Gagata D

Galeichthys D, S

Geneidens D

Glyptosternon D, S

Goldiella S

Helogenes A, D, S

Hemisorubim D, S

Heptapterus $\mathrm{S}$

Hoplosternum D, S

Hypophthalmus A, D, S

Ictalurus A, D, S

Iheringichthys A, S

Leiocassis D

Liobagrus D

Loricaria D, S

Luciopimelodus D, S

Megalonema $\mathrm{S}$
Mystus D

Nematogenys D, S

Notarius D

Osteogeniosus A

Ompok D, S

Oxydoras D

Pangasius $\mathrm{S}$

Pangasianodon D

Parapimelodus $\mathrm{S}$

Perugia S

Phyllonemus A

Pimelodina S

Pimelodus A, D, S

Platystomatichthys D

Plotosus D, S

Pseudauchenipterus $\mathrm{S}$

Pseudobagrus A, D

Pseudocetopsis S

Pseudopimelodus D, S 
Pterodoras D

Rhamdia D, S

Rhinodoras D

Schilbe A, D, S
Silurus D, S

Sorubim A, D, S

Sorubimichthys D, S

Synodontis S
Tandanus D, S

Trichomycterus A, S

Wallago D, S

Abbreviations used in the figures are given either in the relevant sections of the text, or in the figure captions.

\section{Form and function in Hypophthalmus and comparison with other siluroids}

The principal derived features of Hypophthalmus are listed below. The reasons for considering their derived nature are discussed under each character complex.

1. Body shape and pattern of the sensory canals and lateral line system.

2. The position of the eyes and arrangement of their musculature.

3. The hypertrophy of the facial, and the complexity of the hyoid musculature.

4. The particular morphology of the mouth and the articulation of the mandibular barbels with cartilaginous plates.

5. The reduction of the neurocranium and its complete ankylosis with the anterior vertebral complex.

6. The nature of the complex vertebrae, anterior placement of the Weberian ossicles, reduction plus encapsulation of the swimbladder, and displacement of the vagus nerve.

7. The extent of the gill openings and elongation of the branchial arch elements.

8. The elongation and modification of the hyoid arch.

\section{Body shape, sensory canals and lateral line system (Figs $1 \& 2$ )}

Hypophthalmus has a deep and moderately compressed body with a sloped dorsal profile; the head is broad ( $30 \%$ of its length) with a subtriangular snout, the eyes are set at the same horizontal level as the mouth. There is a single pair of long maxillary barbels and two pairs of similarly long mandibular barbels. The gill opening extends almost as far forward as the mandibular symphysis.

The pectoral fin is narrowly triangular, its tip reaching beyond that of the small pelvic fin. The first ray of the pectoral fin is spinous and finely serrated along its outer margin. The anal fin is long with $c .62$ branched rays, extending from the tip of the pelvic to below the adipose fin. The dorsal fin is short-based with $\mathrm{I}+6$ rays; the small adipose fin lies midway between the dorsal fin and the origin of the forked caudal fin.

In life, Hypophthalmus edentatus has a silvery blue-green colour, the barbels are dark, the fins hyaline but with dusky tips to the pectorals, and a dark submarginal band on the anal fin.

The skin above the orbit is permeated with a network of canals which are denser and more ramified below the frontal margin than elsewhere (Fig. 2). The entry points to this network are through the pterotic and frontal sensory canal openings. Similar ramified patterns occur over the antero-dorsal and ventral portions of the operculum. Their respective connections are with the pterotic and preopercular canals.

The lateral line has dorsal and ventral branches. The longest dorsal branches are angled caudally at $45^{\circ}$ to the main lateral line, some extending almost to the dorsal midline; shorter branches run cranially at a similar angle, thus forming a network (Fig. 1).

The longest ventral branches extend to the base of the anal fin where they curve caudally almost at a right angle (one or two branches curve anteriorly). Shorter, angled branches cross the upper part of the vertical lines and form the ventral counterpart of the dorsal network. The lateral line is bifurcated caudally, the longer arm, itself often sub-branched, extends to the 6th or 7th ray of the upper caudal lobe. The lower branch hardly reaches the base of the caudal fin and is absent in some specimens. 


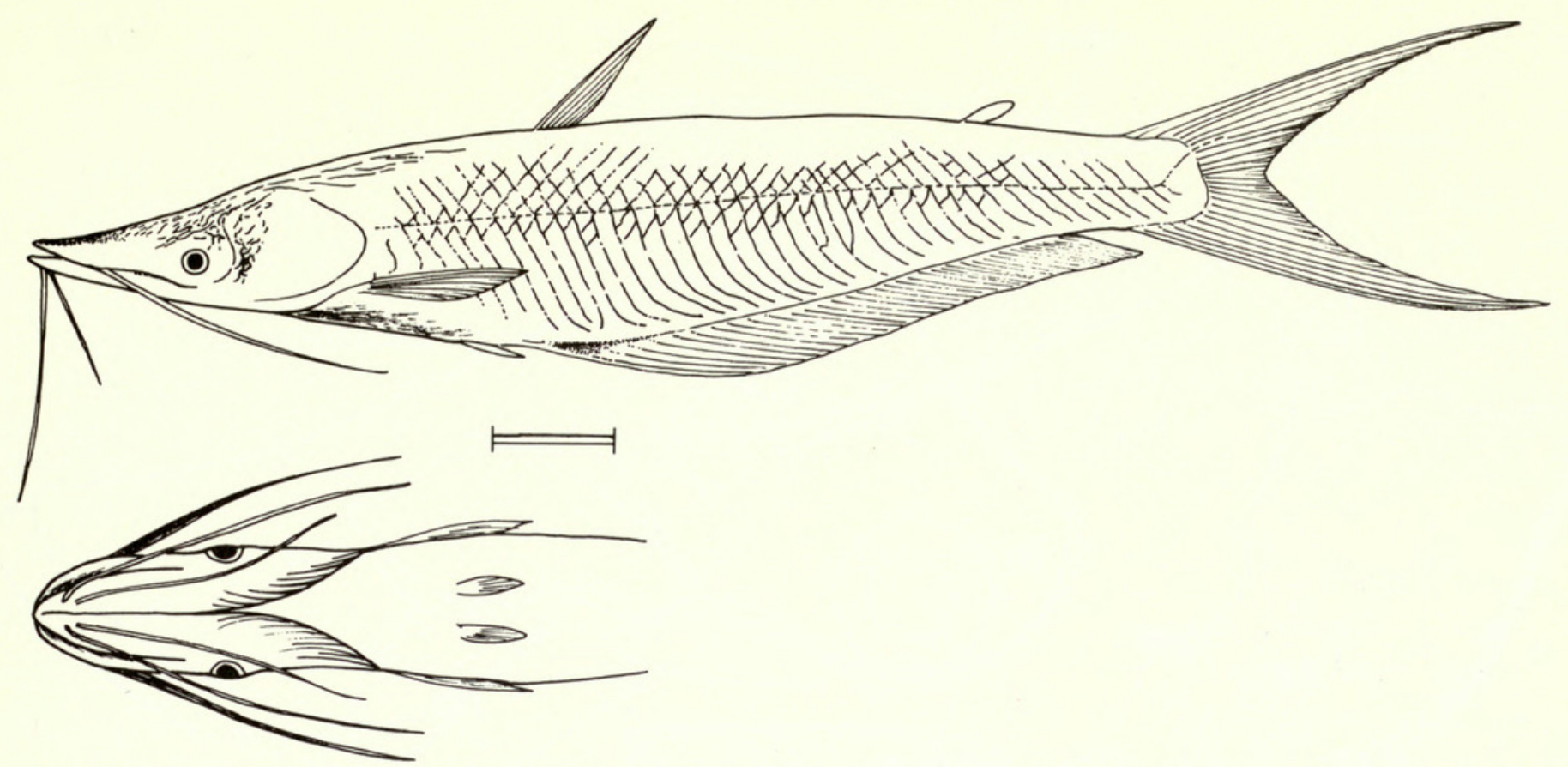

Fig. 1 Hypophthalmus edentatus; (upper) lateral view showing ramifying lateral line system; (lower) ventral view of head to show inferior position of the eye. Scale $=20 \mathrm{~mm}$. Drawn from specimen BMNH 1925. 10.28:327.

The body shape of Hypophthalmus is like that described by Alexander (1965) for the African siluroid Schilbe. The salient features noted by Alexander of the schilbeid morphotype are a compressed trunk; long anal fin; short body cavity; reduced dorsal and adipose fins; deep epaxial musculature reaching well-forward on the cranium and the supraoccipital bearing a tall median crest onto which most of the dorsal musculature attaches. All these features apply to Hypophthalmus and occur also in Old-World siluroids (Siluridae e.g. Ompok, Cryptopterus; Schilbeidae, Pangasiidae) and the Neotropical Auchenipteridae (Auchenipterus) and Ageniosidae. As such it seems to be a morphotype independently derived in several lineages. Nonetheless, such a body shape is assumed to be a derived feature for each group in which occurs as it is always accompanied by some marked, but different modification of the swimbladder and, or, lateralis system.

Carvalho (1980a) found a high proportion of fat in Hypophthalmus (up to $26 \%$ body weight) which varied inversely to the total water content. This high fat content doubtless contributes to the attainment of neutral buoyancy and appears to be a correlate of a reduced swimbladder (see p. 28).

A highly ramified lateral line system similar to that in Hypophthalmus is also found in siluroids and pangasiids, but in no other taxon investigated do the lower branches extend so far ventrally or curve along the anal fin base. An orbital and opercular canal system like that of Hypophthalmus occurs similarly only in Luciopimelodus. A ramifying of canals are present on the cranial and postcranial regions of many siluroids, but generally as separate twiglets over the head and upper opercular region only. In the Ageneiosidae and Pimelodidae alone is there a lattice-like pattern aproaching that of Hypophthalmus. Furthermore, only in Brachyplatystoma and Luciopimelodus does such a system of canals cross the interoperculum. Other siluroids with a similar body shape to Hypophthalmus (e.g. Pangasius, Schilbe, Ompok) lack an intricate epidermal network.

Alexander (1965) observed that catfishes possessing the schilbeid morphotype (see above) were more pelagic than others, and accounted for the compressed, tapered body shape in terms of a specialised locomotion. A principal component of schilbeid locomotion is the ability to hover by inclining the body at a $45^{\circ}$ angle to the surface. It has not been reported whether Hypophthalmus adopts a similar locomotory attitude. Neither is it clear whether Hypophthalmus should be classed as 'pelagic' for it seems that these fishes may make vertical migrations (Meschkat, 1960). 


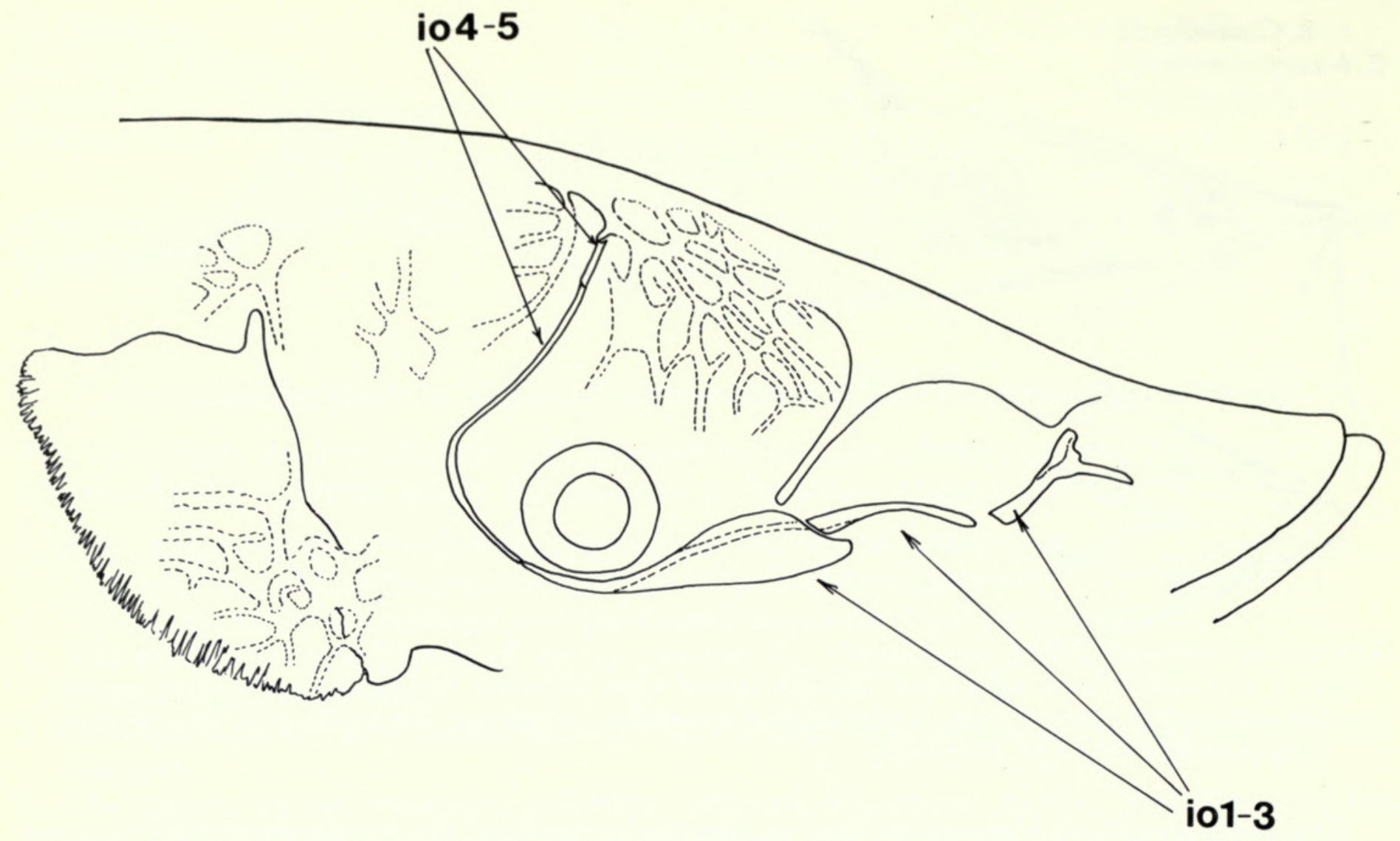

Fig. 2 Hypophthalmus edentatus lateral view of head showing sensory canal system and infraorbitals. Composite drawing.

The eye and infraorbital bones (Figs 2-4)

Two of the more noticeable features of Hypophthalmus are the position of the eye relative to other parts of the cranium, and the arrangement of the orbital muscles (Fig. 3).

The eye is of moderate size (12\% of head length) and is situated on the ventral margin of the head at the same horizontal level as the mouth. When viewed ventrally the eyes appear as almost entirely inferior (Fig. 1).

The eye muscles, in their origins and position lateral to the adductor muscle complex, are unlike those of any other siluroid. The anterior muscles are long and strap-like. Both the superior obliquus (sob) and inferior obliquus (iob) have a common origin from a broad tendinous sheet that extends dorsally across the adductor mandibulae musculature to attach to the lateral margin of the frontal and to the lateral ethmoid. The optic nerve and those supplying the eye muscles all run parallel to one another within an almost vertical band of connective tissue. As in other siluroids the superior obliquus is innervated by the trochlear nerve (niv) and the inferior obliquus by a branch of the oculomotor (niii). The rectus internus (ri) arises from a thin tendinous strand that crosses the face of the adductor complex and runs between the superior obliquus and inferior obliquus muscles to attach to the anteromedial surface of the eyeball. The muscle is unnervated by a sub-branch of that branch of the oculomotor that feeds the inferior obliquus.

The posterior set of muscles, rectus superior, $r$. inferior and r. externus (Fig. 4, rs; rin; re) originate from a tendinous band which is strongly attached to the dermis. The former two muscles are innervated by branches of the oculomotor and the latter by the abducens (nvi).

The optic nerve (nii) is thick and exits from a slit-like foramen to loop over the adductor muscle complex and pass across its face which is grooved to accommodate it.

The infraorbital bones (io Fig. 2) are, with the exception of the 3rd, reduced to ossifications of the sensory canal. The 1st infraorbital is axe-shaped, the common morphology of this element amongst siluroids, the 2 nd a slightly curved, cylindrical bone, the 3 rd with an 

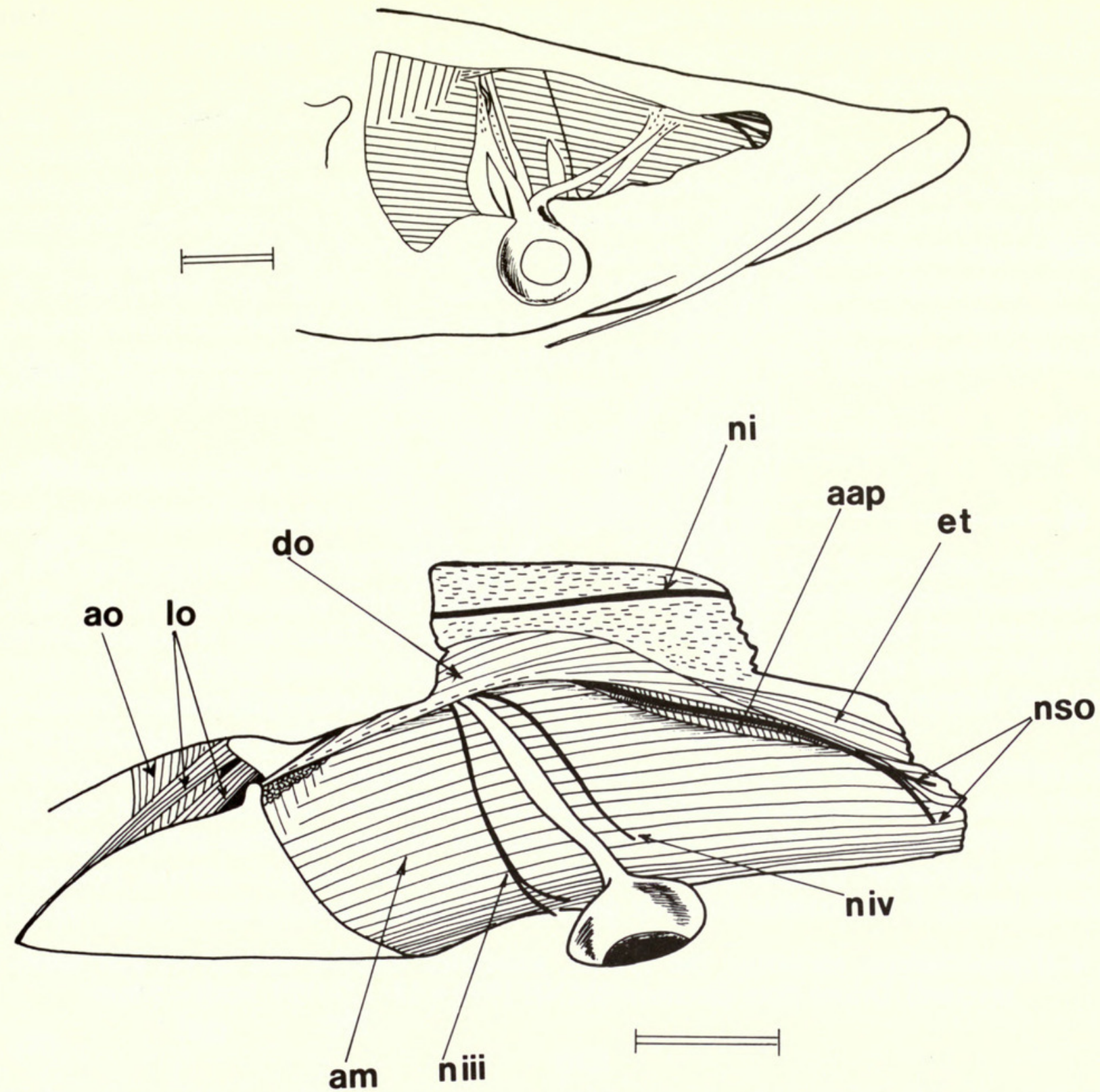

Fig. 3 Hypophthalmus edentatus; (upper) superficial dissection of the head showing position of the eye muscles in relation to the cheek musculature; (lower) dorsal view of orbital region (eye muscles removed) with frontal cut away to display the dilatator operculi muscle (do) and olfactory nerve (ni). Drawn from specimen BMNH 1976.6.18: 123-129. Scales $=5 \mathrm{~mm}$. $\mathrm{am}=$ adductor mandibulae; $\mathrm{nso}=$ rami of supraorbital nerve trunk.

antero-ventral lamellae, its posterior, tubular portion lying beneath the orbit; the 4th, the largest of the series, curves dorso-posteriorly to beyond the border of the eye, then, at the upper level of the orbit, curves dorso-anteriorly to extend across the interspace between the orbit and the cranium; the 5 th a small tubular bone connected to the pterotic.

Although unusual, the ventro-lateral position of the eye in Hypophthalmus is not unique amongst siluroids. It occurs similarly in Ageniosus, some Auchenipterus and Pangasius species. However, in all these taxa, the arrangement of the eye muscles is of the more normal teleost condition.

In both Auchenipterus and Pangasius the eye ball is cupped by the surrounding muscles, the posterior set passing into the optic foramen. Ageniosus is markedly similar to Hypophthalmus in the displacement of the optic nerve tract across the adductor muscle face. However, the musculature is extended laterally and there is a consequent orientation of the nerve tract, unlike the vertical course followed in Hypophthalmus. Furthermore, the eye muscle arrangement in Ageniosus is less modified in that the posterior muscles, although highly tendinous, join in a single cylindrical tract across the adductor mandibulae muscle. 

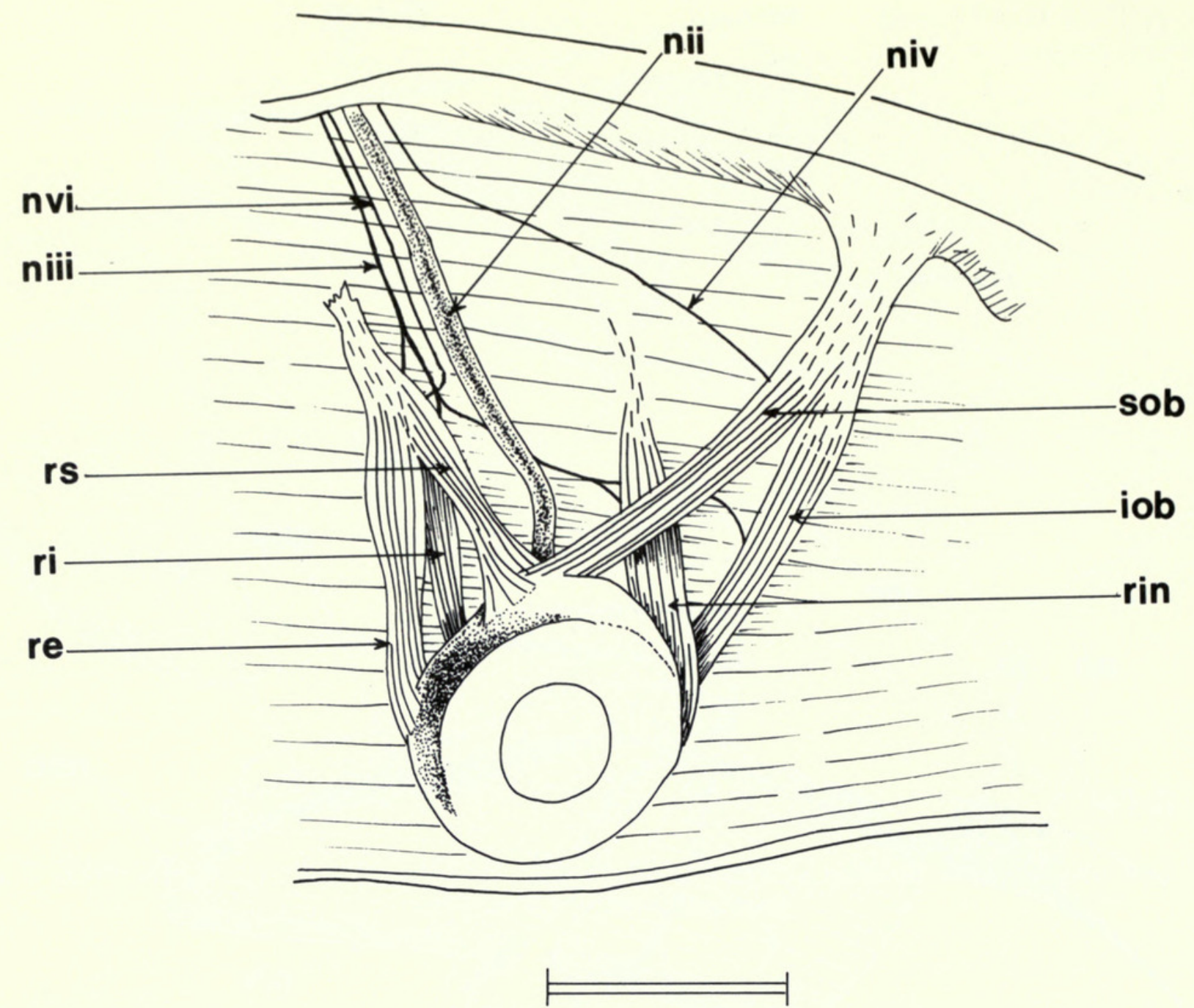

Fig. 4 Hypophthalmus edentatus; the eyeball, associated muscles and nerves (the upper skin reverted). Drawn from specimen BMNH 1976.6.18: 123-129. Scale $=5 \mathrm{~mm}$.

Only in the pimelodid Sorubimichthys is there a muscle arrangement approaching that of Hypophthalmus. Although in the former genus the eye is superior in position and the posterior set of muscles are horizontally aligned, the anterior muscles originate from a tendinous band above the extensor tentaculi muscle (et Fig. 10).

The inferior orientation of the eyes in Hypophthalmus may provide a partially stereoscopic vision which would serve to alert the fish to an approaching predator. The degree of eye mobility in Hypophthalmus is unknown. The eye muscles are thinner, and appear 'weaker' than in the other taxa investigated, but their complete innervation suggests some degree of eye-ball movement.

According to Dullemeijer \& Barel (1977) the eye in teleosts is a functionally dominant feature and in their opinion one with little positional plasticity. This is obviously not the case in Hypophthalmus where the eye has shifted ventrally from the usual siluroid superolateral position. In Hypophthalmus the position of the eye has apparently been 'dictated' by the form of the adductor muscle complex. This is in direct contrast to phytoplankton feeding percomorphs (Dullemeijer \& Barel, 1977) where the eye has retained a superior position and consequently only a small area is available in which the adductor muscle can develop and operate.

In general, the eyes of siluroids appear to have a less dominant role than in other otophysans or indeed other teleosts. In many siluroids the trend has been for the eyes to have shifted into a superior position, taken to the extreme in some loricarioids (e.g. Chaetostoma and Astroblepus) where the orbits are separated by a minimal space. 
Fink \& Fink (1981) claim that the infraorbital series in siluroids is reduced to the canal bearing portion of the bone. Whilst this is true for the majority of taxa it does not hold for all; Hypophthalmus is one exception (see above). In the clariids, the posterior infraorbitals (includes 'supraorbital' aucct.) are greatly expanded.

The recognition of reduced infraorbitals and the absence of a supraorbital bone as synapomorphies linking siluroids with gymnotoids (Fink \& Fink, 1981) is dubious. Such reduction and loss also occurs in cyprinoids (Cobitidae). An even more pertinent point is the differing arrangement of the infraorbitals in gymnotoids and siluroids-clearly shown by Fink \& Fink (1981, fig. 7D-E). The anterior infraorbital bones of siluroids are always elongate and the 3 rd extends someway past the orbit so that the posterior series curve dorsoanteriorly. In gymnotoids the $3 \mathrm{rd}$ infraorbital is a short bone and the posterior elements are directed diagonally in a dorso-posterior direction.

\section{Cranial musculature (Figs 5-6)}

Jaw and suspensorial muscles

When the eye, together with its muscles and the optic tract have been removed, the entire face of the fish is seen to be covered by an almost undifferentiated adductor muscle (Fig. 5). The orbital socket is indicated on the face of the muscle by a circular tendinous area, the optic tract by a vertical groove (otf, Fig. 5). Dorso-posteriorly, lateral fibres of the levator arcus palatini muscle (lap) adhere to the adductor's surface, and a more medial section of the levator is indicated by a longitudinal division of the adductor.

The posterior origin of the adductor mandibulae is from the lateral and antero-medial faces of the hyomandibula. Anteriorly, at the articulation of the lower jaw, there is a myocomma and the adductor can be differentiated into a number of segments. The upper, outer portion curves inward, its anterior border being tightly attached to the thick mandibular nerve tract (nvmd) which follows the muscles contour as it passes medially to

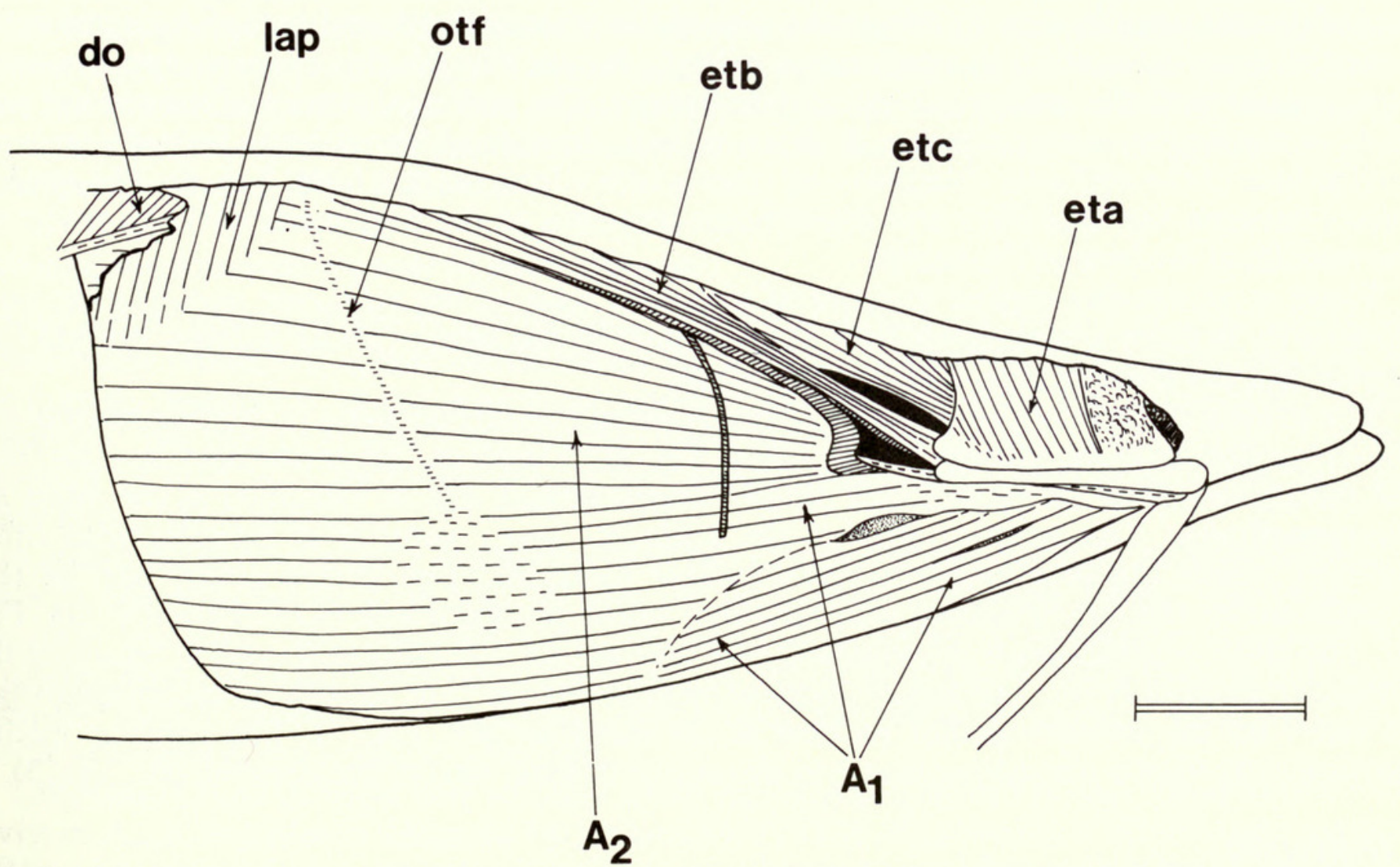

Fig. 5 Hypophthalmus edentatus; superficial head musculature. Drawn from specimen BMNH 1976.6.18: 123-9. Scale $=5 \mathrm{~mm}$. 


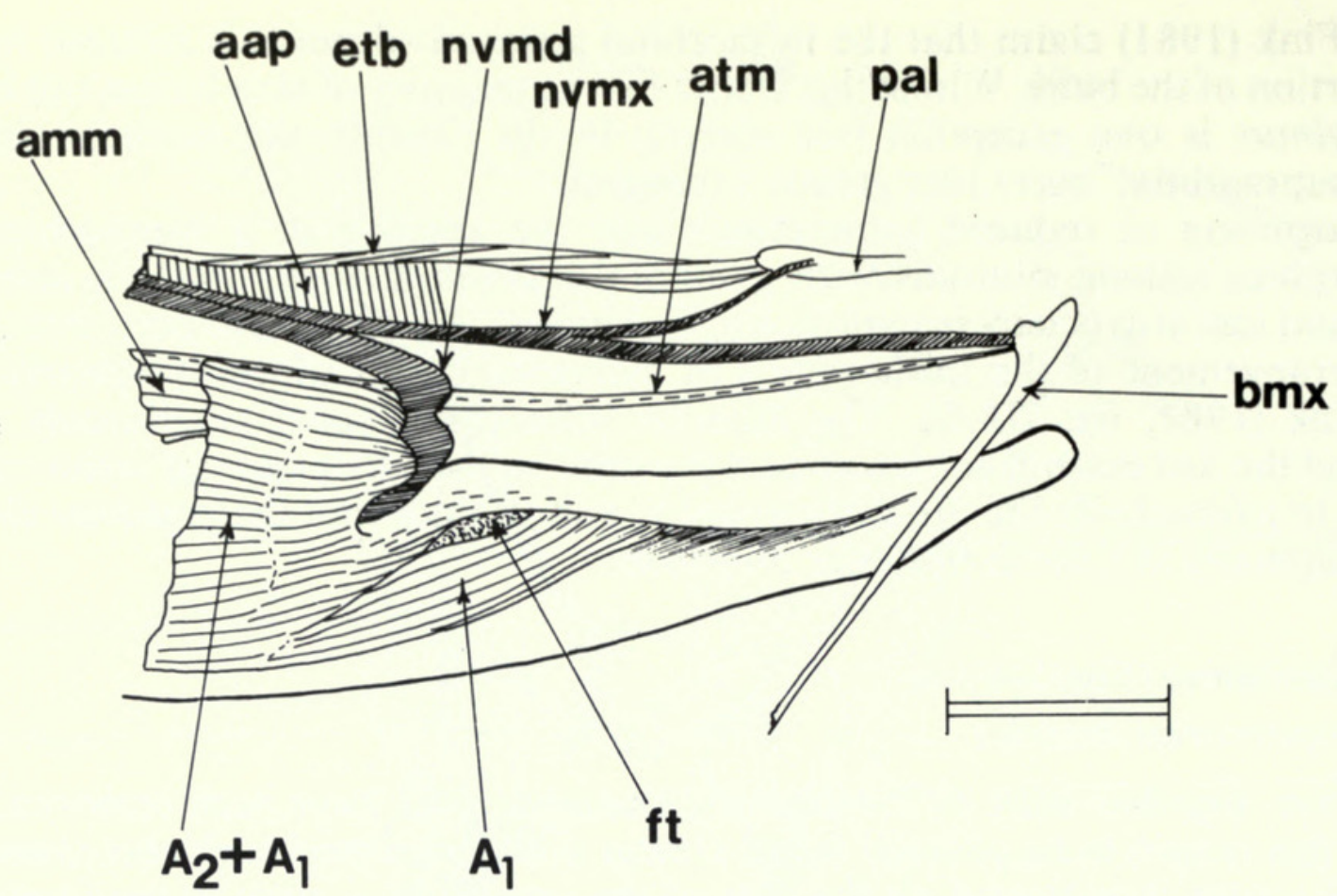

Fig. 6 Hypophthalmus edentatus; lower jaw musculature. The palatine and extensor muscle have been raised. In relaxed position the tendon (atm) passes between the rami of the maxillaris nerve $(n v m x)$. Drawn from specimen BMNH 1976.6.18: 123. Scale $=3 \mathrm{~mm}$.

attach to the inner face of the lower jaw. From its insertion this part of the muscle is regarded as section $\mathrm{A}_{2}$ (Fig. 6). There is no recognisable $\mathrm{A}_{\mathrm{w}}, \mathrm{A}_{2}$ inserting via a broad tendon stretching across the medial face of the adductor mandibulae mass.

The antero-ventral part of the muscle lying lateral to the mandibularis nerve trunk is divisible into an upper bundle of fibres inserting into the lip tissue covering the coronoid process, and a ventral section inserting partially into labial tissue and partially on the lateral face of the dentary ( $A_{1}$, Fig. 5). When the superficial layer of the dorsal part of $A_{1}$ is removed, a medial layer is found to be continuous with $\mathrm{A}_{2}$ (amm, Fig. 6); this division appears to be homologous with the retractor tentaculi (see below). The posterior border of the ventral part of $A_{1}$ is marked by a myocomma. A short, pinnate bundle of fibres stems from the anteromedial face of the adductor complex and inserts into a long tendon (atm, Fig. 6). The tendon passes between the maxillary and mandibular branches of the trigeminal nerve to insert on the maxilla at the base of the barbel.

There is no discrete medial division of the main body of the adductor mandibulae, only posteriorly is there a separation by a medial sheet of the levator arcus palatini muscle (see above), but the fibres of both muscles intermesh.

The central portion of the adductor arcus palatini extends between the parasphenoid and the dorsal border of the pterygoid bones (aap, Fig. 6). A separate, posterior portion runs from the parasphenoid to the medial face of the hyomandibula, and is identified as the adductor hyomandibulae. The anterior part of the adductor arcus palatini is divisible into three sections which together comprise the extensor tentaculi. The antero-dorsal part of this muscle covers the lateral ethmoid and attaches to the posterior half of the palatine (eta, Fig. 5 ). The postero-medial part originates as two separate sections from the central region of the adductor arcus palatini. The longer, postero-medial section runs forward at an oblique angle to insert on the postero-medial portion of the palatine (etb, Fig. 5). The shorter, medial portion runs antero-dorsally to insert on the antero-medial part of the palatine (etc, Fig. 5).

\section{Innervation}

Two thick nerve tracts stem from the trigeminofacial ganglion and exit from a single prootic foramen. The supraorbital trunk diverges immediately. The infraorbital trunk is of great 


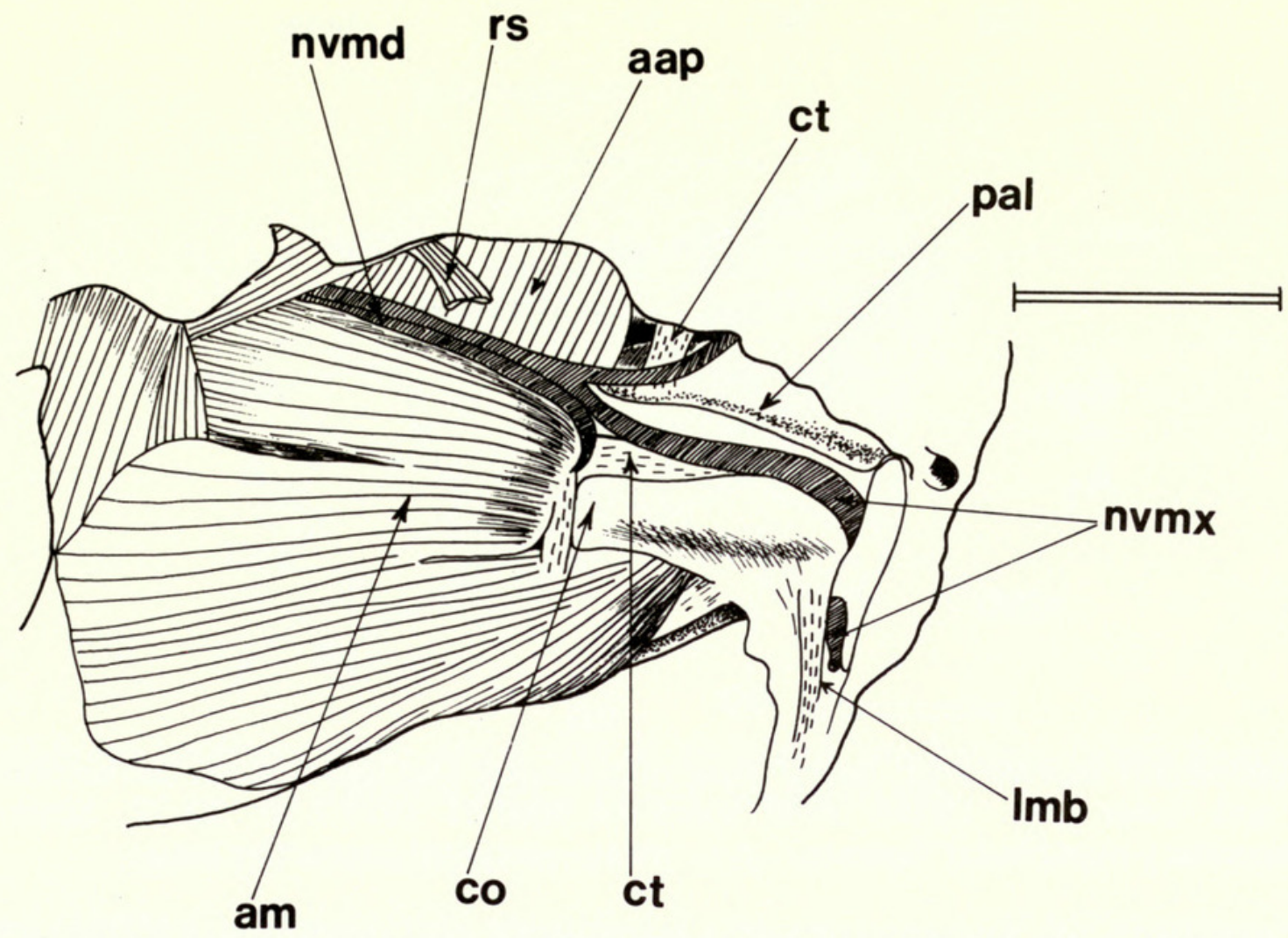

Fig. 7 Nematogenys inermis; dorso-lateral view of cheek musculature. Drawn from specimen BMNH 1883.11.27: 45-48. Scale $=10 \mathrm{~mm}$. co=coronoid process; $\mathrm{ct}=$ connective tissue; $\mathrm{lmb}=$ ligament connecting maxillary barbel with mandible.

thickness, and above the jaw articulation it divides into the buccal and maxillo-mandibular rami which pass, respectively into the root of the maxillary barbel and the lower jaw. (Fig. 6). The buccal ramas gives off a branch to the adductor arcus palatini before bifurcating into an outer branch serving the area of the extensor tentaculi muscle around the palatine, and an inner branch which enters the base of the maxillary barbel. The mandibular ramus (nvmd) curves round the anterior border of the adductor muscle complex, sending off short branches into the musculature (Fig. 6). The trunk passes across the inner face of the dentary to run inside the length of the bone before terminating in a bifurcation, each branch of which enters its respective barbel (Figs $7 \& 14$ ).

\section{Jaw and suspensorial muscles in other siluroids}

It is generally accepted (see Winterbottom, 1974) that in teleosts the section of the adductor mandibulae termed $\mathrm{A}_{1}$ is that which forms the outer, or dorsal muscle segment inserting on the maxilla. Section $A_{2}$ is that which lies medially and, or, ventrally to $A_{1}$, and inserts on the lower jaw; the part of it which covers the medial face of the dentary is termed $A_{w}$. Further divisions $\left(A_{2} a, A_{3}\right.$ etc) are those successively medial to $A_{1}$ and $A_{2}$ and which insert onto the inner face of the lower jaw.

In siluroids, this seemingly straightforward nomenclature has become somewhat confused through the presence of a muscle, serving the base of the maxillary barbel, known as the retractor tentaculi, often referred to as the adductor tentaculi or protractor maxillae; see Winterbottom, 1974 for synonymy. The fact that this muscle inserts on the maxilla but stems from the medial aspect of the adductor mandibulae has led to its being homologised with various sections of the adductor complex.

Takahasi (1925) thought that because of its maxillary insertion it was synonymous with division $\mathrm{A}_{1}$, a hypothesis followed by Edgeworth (1935). McMurrich (1884b) and Lubosch (1938) considered the retractor tentaculi to be an inner division of the adductor. Eaton (1948) agreed, in referring to Ictalurus thus ...'From the fact that a stout ligament runs from the base of the adductor tendon back and downward to join the ligamentous sheath of the 


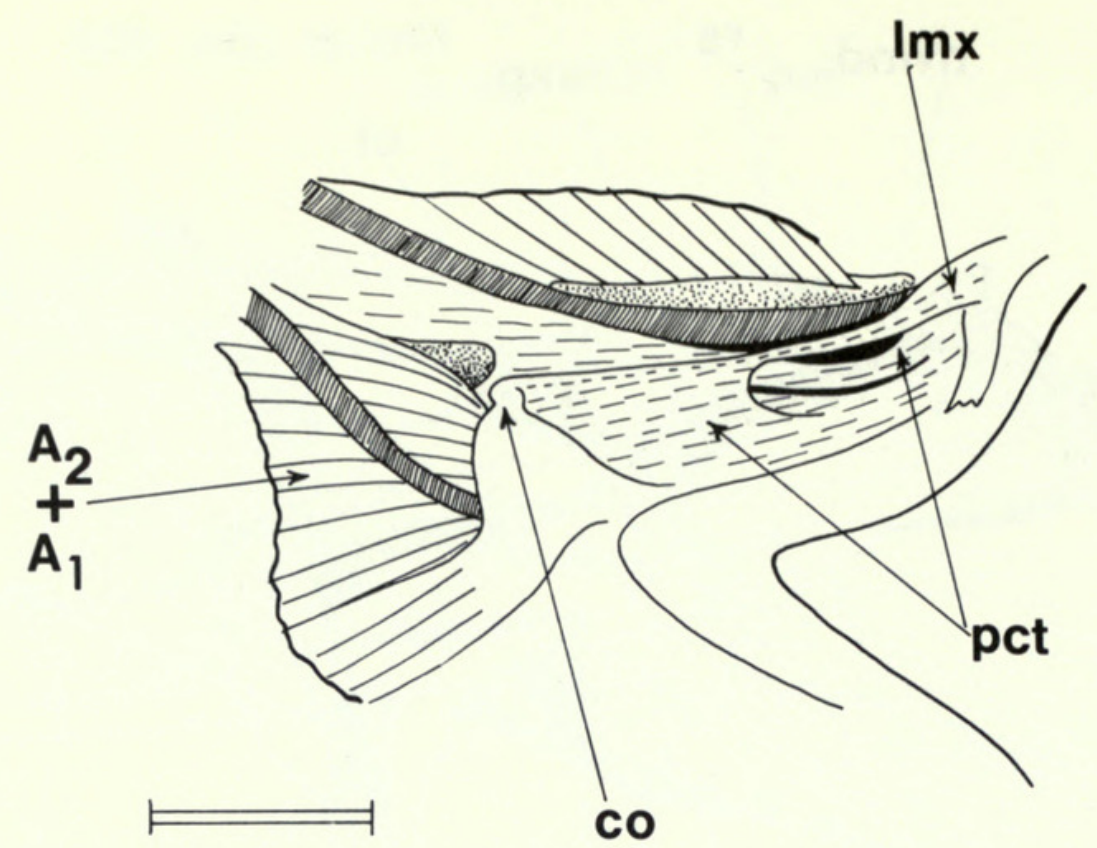

Fig. 8 Callophysus macropterus; lateral view of muscular and ligamentous connections to the upper and lower jaws. Drawn from specimen BMNH 1913.7.30: 20-22. Scale $=5 \mathrm{~mm}$. $\operatorname{lm} x=$ maxillary-mandibular 'ligament'; $p c t=$ palato-pterygoid connective tissue.

quadrato-articular joint, I would infer that the muscle has simply taken hold, as it were, of the primitive ligament which runs, in such fishes as Amia calva, from the articular to the maxillary. Thus, the ligament has now become in large part a muscle tendon. ..'

Alexander (1965) concurs with Eaton, believing that the retractor tentaculi (the adductor tentaculi of Alexander) is derived from '. . . $\mathrm{A}_{3}$ rather than $\mathrm{A}_{1}$ '.

From the arrangement in siluroid taxa I have investigated, it appears that these latter authors are probably correct in assuming that the retractor tentaculi is part of the inner adductor series and that its attachment with the upper jaw is a de novo development. The possible evolutionary development of the retractor tentaculi as suggested by Eaton (1948) and Alexander (1965) can be amplified by the following observations.

The presumed plesiomorph condition of the adductor mandibulae muscle in siluroids is where divisions of the muscle are not well-differentiated and insertion is entirely, or almost entirely, on the lower jaw. Diplomystes and Nematogenys (Fig. 7) illustrate this condition where the lower, outer part inserts musculously on the lower jaw (anguloarticular). An upper, inner division can be distinguished by its attachment, anteriorly, to the lower part by a broad vertical tendon which covers the postero-dorsal rim of the lower jaw. Stemming from the antero-medial surface of this muscle, and extending across the dorsal surface of the mandible is a thick sheet of connective tissue (ct). This sheet bifurcates, the upper strand attaching to the posterior face of the maxilla, the lower to the distal portion of the maxilla where it forms a sheath around the maxillary barbel.

In Callophysus, Pimelodidae, a continuous sheet of tissue extends medially from the dentary to the anterior pterygoid process (pct, Fig. 8). That area of tissue covering the coronoid process is thickened and, anteriorly, is separated from the main sheet so forming a distinct 'ligament' running to the base of the maxillary barbel ( $\operatorname{lmx}$, Fig. 8).

A similar arrangement of the 'ligament' is present in Tandanus and Plotosus. Alexander (1965), following Takahasi (1925), states that the deepest part of the adductor mandibulae inserts on the articular-maxillary ligament. This is, however, incorrect. A strong ligament does indeed stretch from the posterior aspect of the maxilla to the coronoid process of the dentary, and appears to be homologous with the partially differentiated 'ligament' described above in Callophysus, but no muscle inserts on it (lmx, Fig. 9). The outer portion of the adductor mandibulae in Tandanus and Plotosus inserts on the lower jaw medial to the ligament. The inner sections of the adductor, be they interpreted as $\mathrm{A}_{2}$ or $\mathrm{A}_{3}$, insert on the medial face of the anguloarticular (Fig. 9). 


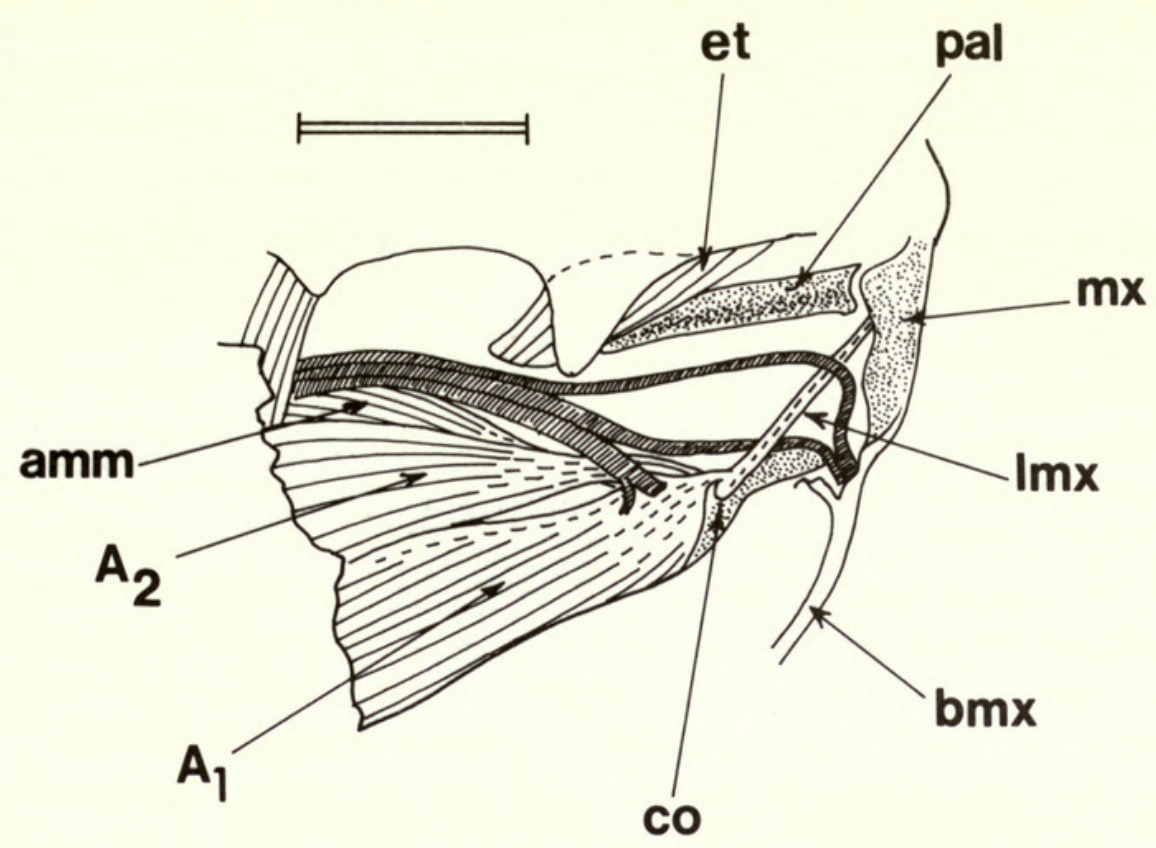

Fig. 9 Tandanus tandanus; dorso-lateral view of jaw muscle attachments. Drawn from specimen BMNH 1871.2.10: 4-6. Scale $=10 \mathrm{~mm}$.

Kesteven (1943) also erroneously identified a retractor tentaculi, his protractor maxillae, in Tandanus. He states that the muscle '. . . arises from the side of the skull above the anterior attachment of the palatal arch...' to insert on the maxilla '... enswathing the posterior end of the bone.' I find no such muscle in Tandanus tandanus (Fig. 9) nor in Plotosus plotosus and must presume Kesteven misidentified part of the extensor tenatculi or else did not entirely dissect the connective tissue enswathing the maxilla.

In the pimelodids Pimelodus and Iheringichthys and the bagrid Clarotes a distinct ligament connects the base of the maxillary barbel with the coronoid process of the dentary. However, the ligament then courses posteriorly from the coronoid process to the fascia of the medial section of the adductor mandibulae. A further modification of this condition occurs in one group of pimelodids, Parapimelodus and Pimelodus maculatus, whereby there are two distinct ligaments extending from the base of the barbel, the outer attaching to the coronoid process and the medial one to the pterygoid process. In none of these taxa does the musculature attach to the ligaments.

In Megalonema, Pimelodidae, the maxillo-articular ligament bifrucates posteriorly, the inner branch becoming continuous with the tendon of the medial segment of the adductor muscle complex. The outer ligament is, however, still connected with the lower jaw. In Sorubimichthys, Pimelodidae, a distinct ligament connects the maxilla with the coronoid process of the dentary. However, the ligament is tightly attached along the length of the upper jaw (premaxilla) by connective tissue. A branch of the mandibularis nerve runs into the tissue joining the upper and lower jaws (Fig. 10).

These examples serve to illustrate the probable pattern involved in the evolution of the retractor tentaculi. The hypothesised stages of this process are; (1) the palato-mandibular connective tissue becomes differentiated to form a stout, free ligament connecting the maxilla with the posterior part of the lower jaw, (2) medial fibres of the adductor mandibulae become associated with the maxillo-palatine part of the palato-mandibular tissues, (3) the connective tissue becomes further differentiated and tendinously links a discrete medial section of the adductor mandibulae with the root of the maxillary barbel.

The basic conditions for the development of the retractor tentaculi are present in several members of the Pimelodidae, Bagridae and Plotosidae and it seems very likely that the muscle has been derived independently in several lineages. Various apomorphic conditions of the muscle can be recognised as for example in some pimelodids such as Rhamdia where the anterior segment is attached to the orbitosphenoid via a bifurcated tendon. 


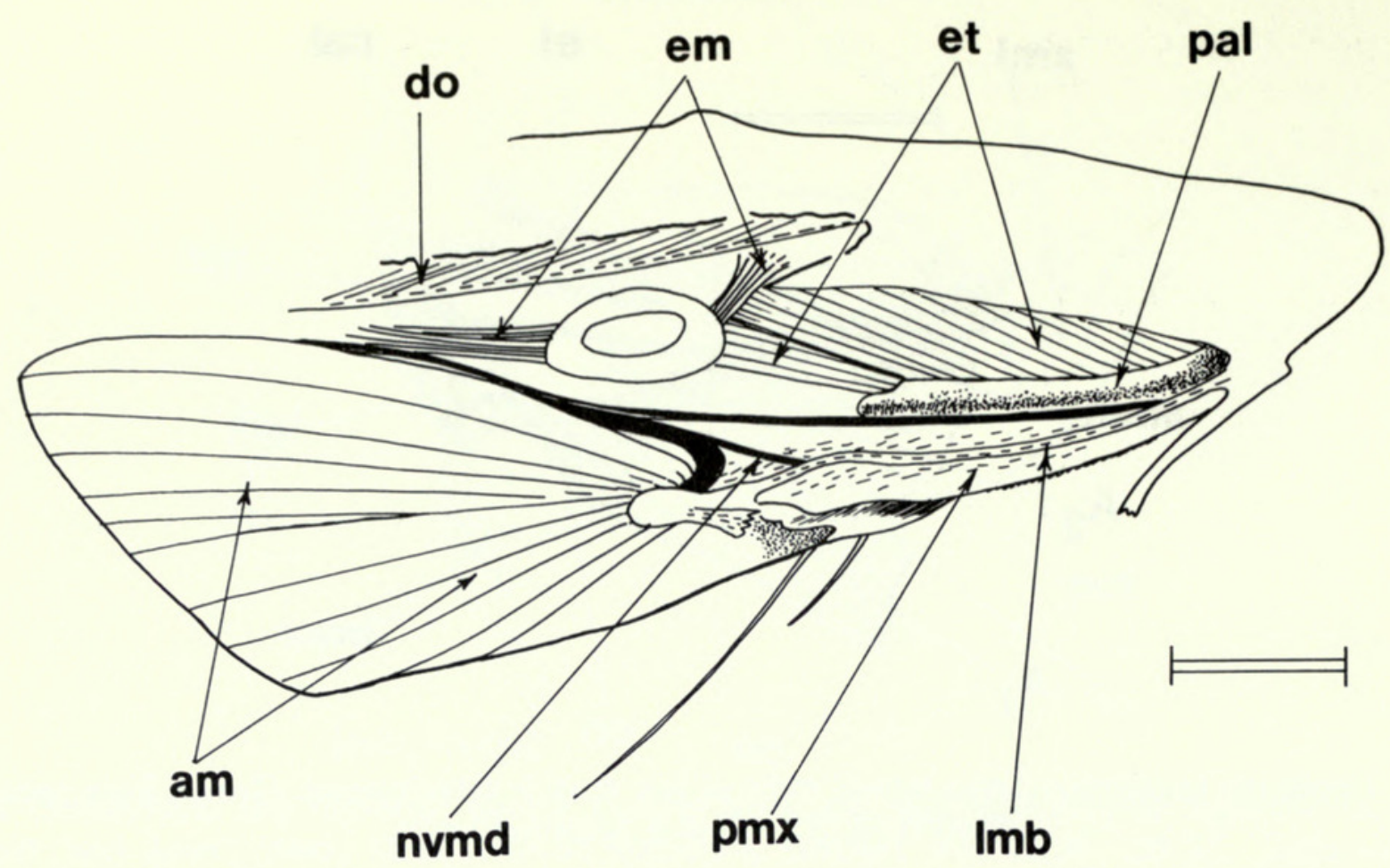

Fig. 10 Sorubimichthys planiceps; dorso-lateral view of superficial jaw musculature. Drawn from specimen BMNH 1977.5.24: 12. Scale $=5 \mathrm{~mm}$. em = eye musculature, $1 \mathrm{mb}=$ maxillary barbelmandibular ligament.

If the adductor mandibulae muscles of siluroids are compared with those of other otophysans, their arrangement is seen to correspond most closely to that of characoids, where section $A_{1}$ also inserts on the dentary. Vari (1979: 317) considered that a lower jaw insertion for the outer part of the adductor represented the plesiomorph condition. In characoids a strong, well-differentiated maxillary-mandibular ligament is present and often the dorso-lateral fibres of $A_{1}$ attach to this ligament. Vari (1979) notes that incorporation of the ligament into the tendon of $\mathrm{A}_{1}$ is a derived condition in distichodontid characoids.

In cyprinoids the section $A_{1}$ never inserts on the lower jaw and there is no maxillarymandibular ligament.

In gymnotids there is a maxillary-mandibular ligament and in Gymnotus a few fibres of the outer part of the adductor muscle insert on this ligament; the remainder of the muscle inserts onto the outer face of the lower jaw, as in siluroids. However, this is not the case in Sternopygus, Eigenmannia and Rhamphichthys the only other gymnotid taxa examined, where the outer segment of the adductor attaches to the 1st infraorbital in Sternopygus and Eigenmannia, and to both the 1st infraorbital and the maxilla in Rhamphichthys.

Two hypotheses are available to account for the arrangement of the outer adductor muscles in siluroids. 1. That the insertion on the lower jaw is plesiomorphic and the ligamentous strand connecting the maxilla with the dentary is homologous with that similar ligament in characoids. 2 . That insertion on the lower jaw is a derived feature brought about by regression of the maxilla and the loss of its intimate connection with the lower jaw. In effect, a regression of the cyprinoid condition.

Fink \& Fink (1981) favour the second hypothesis stating ...'The conditions in some characiformes and in siluriformes are hypothesised to be secondary reductions from a primitive attachment to the maxilla.' Although Fink \& Fink refer to some Characiformes, the outer element of the adductor mandibulae attaches to the lower jaw in the majority of characiform taxa. In those siluroids where the adductor mandibulae inserts on the upper jaw, Loricariidae, Astroblepidae, it is to the premaxilla and the muscles involved are derivatives of the medial and not the outer parts of the adductor complex (Howes, in press). Only in the Callichthyidae is there an insertion of $\mathrm{A}_{1}$ on to the maxilla, and this appears to be a derived condition associated with the maxillary-ethmoid joint (Howes, in press). In view of these 
observations I would regard a lower jaw insertion of the adductor madibulae $\mathrm{A}_{1}$ in siluroids as the plesiomorph condition. The use of this character by Fink \& Fink (1981) uniting the siluroids and the gymnotoids cannot be upheld, as in some (?the majority) of gymnotoids, the outer part of the adductor muscle inserts on the 1st infraorbital and not the lower jaw (see above).

\section{The opercular muscles (Figs $3 \& 5$ )}

The dilatator operculi (do, Figs $3 \& 5$ ) is an exceptionally long muscle having its area of origin anterior to the orbit, the fibres adhering to, and covered by, the ventral margin of the frontal. Posteriorly, above the optic tract, the muscle is exposed before becoming tendinous and passing between the adductor mandibulae and the medial section of the levator arcus palatini. The long insertion tendon attaches to the antero-dorsal process of the operculum.

The levator operculi (lo Fig. 3) comprises two thin segments, an upper one arising from the postero-dorsal face of the hyomandibula and inserting on the postero-dorsal margin of the operculum, and a medial one originating from the pterotic and inserting on the anteromedial face of the operculum.

The adductor operculi (ao Fig. 3) originates from a fossa indenting the pterotic, exoccipital and 'posttemporal'. It inserts on the dorso-medial face of the operculum.

\section{The hyoid muscles (Figs 11 \& 12)}

The ventral head muscles have a complex arrangement with much integration of the various segments.

The ventral layer exhibits two groups of muscles; those in which the fibre direction is toward the midline and those in which it runs antero-laterally.

The largest element (hma, Fig. 11A), belonging to the latter group, occupies half the lateral aspect of the lower jaw. Its fibres run at an oblique angle from the anterohyal to the dentary; anteriorly they change direction to run almost longitudinally. The outermost fibres insert onto the forepart of the dentary whilst the remainder turn inward as a separate bundle and are incorporated into the medial section (hmb, Fig. 11A). This medial part of the muscle also originates from the anterior part of the anterohyal. The muscle is formed from two sheets. The ventral, medial portion (hmb1, Fig. 11 A) curves antero-medially, its outer fibres inserting on the cartilaginous plate of the inner mandibular barbel, its inner fibres meeting those of its antimere at a midline raphe. The lateral portion (hmb2, Fig. 11A) runs anteriorly to insert on a tendinous pad covering the cartilaginous base of the outer mandibular barbel (see below). A separate bundle of fibres insert into the base of the barbel. The medial fibres of $\mathrm{hmb} 2$ overlie the lateral aspect of $\mathrm{hmb} 1$, but at the midline both musclelayers meet at a raphe.

Covering the branchiostegal rays and extending forward as a thin, longitudinally fibred segment is muscle hmc (Fig. 11A). Anteriorly it joins an aponeurosis into which hmbl inserts; medially it joins its partner at a midline raphe. Extending forward from the aponeurosis is a discrete bundle of fibres that attaches to the base of the inner mandibular barbel (hmd, Fig. 11 A).

The large muscle (hma) is considered, from its disposition and innervation by the ramus hyoideus VII to be the posterior protractor hyoidei. The inner divisions ( $\mathrm{hmb} 1$ and $\mathrm{hmb} 2$ are also innervated by branches of the r. hyoideus VII and appear to be anterior parts of the protractor hyoidei. The small muscle slip attaching to the outer mandibular barbel is merely a continuation of the dorsal portion of this muscle and can be identified with that element named by Singh (1967) as a retractor tentaculi, not to be confused with his use of this name also for the facial muscle. The longitudinal muscle $(\mathrm{hmc})$ is the hyohyoidei adductores. It is unclear, however, if the small bundle of fibres (hmd) running from its anterior aponeurosis to the inner mandibular barbel is indeed part of this muscle or whether it is derived from the protractor hyoidei. This small barbel muscle should also be identified with Singh's (1967) retractor tentaculi, which Winterbottom (1974) considered to be homologous with the 


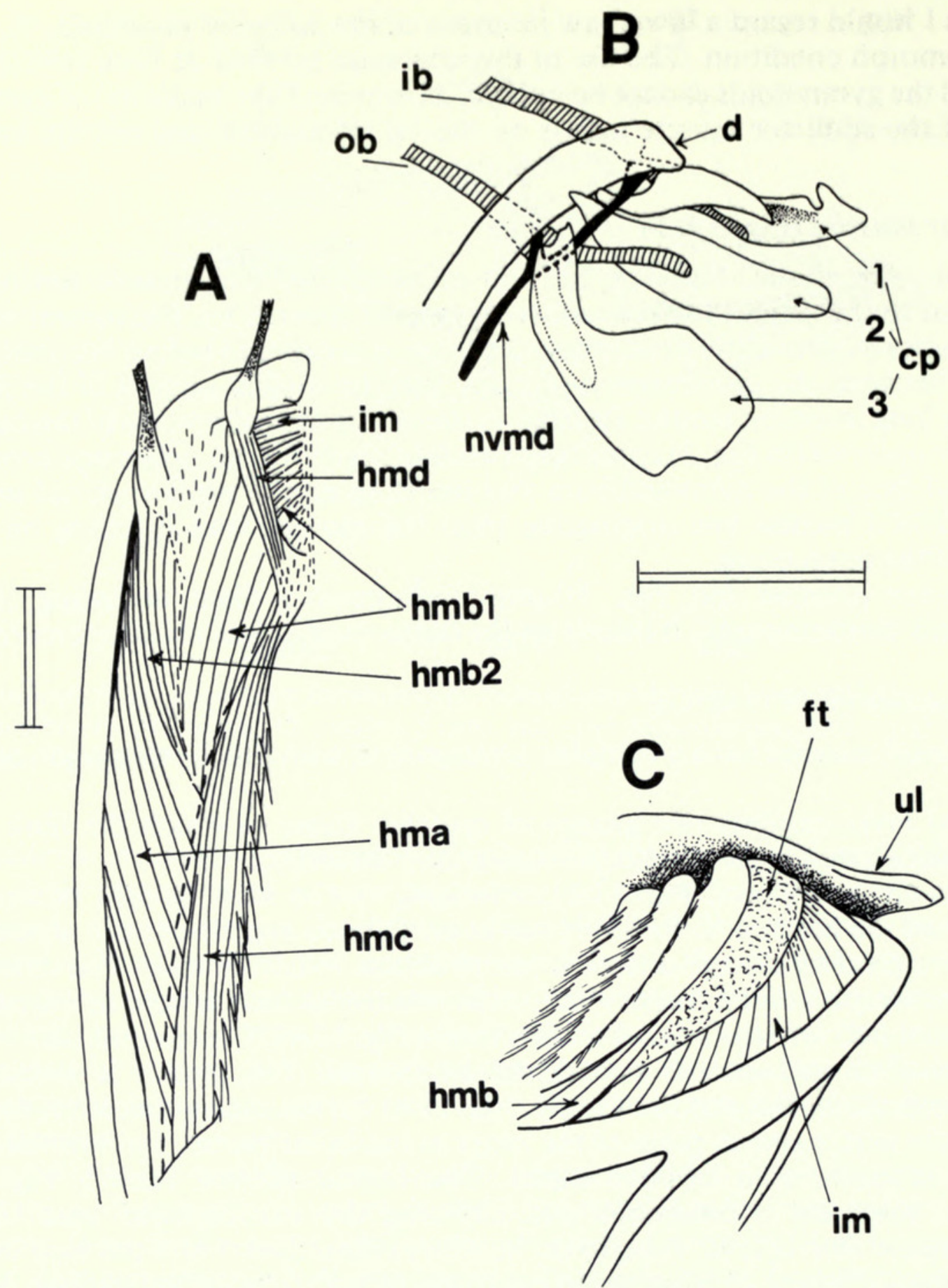

Fig. 11 Hypophthalmus edentatus; A, ventral view of hyoid musculature (right side); B, dorsomedial view of mandibular barbel supporting elements (left side). Thick dashed lines $=$ nerve path, thin-dashes and dots=outline of barbel root; $\mathrm{C}$, lateral view of mouth, upper lip cut sagittally. Drawn from specimens BMNH 1972.7.27: 675-678 \& 1976.6.18: 123. Scales =5 mm $\mathrm{ul}=$ upper lip.

retractor hyoidei. Ghiot (1978) illustrated in Pimelodus five separate muscles controlling the mandibular barbels of which he ascribed origin to 'differentiation of the hyoid protractor'.

The intermandibularis (im, Figs 11A \& C) forms the anterior transverse muscular floor of the mouth. It is divided medially and each segment is attached to its respective cartilaginous plate which serves to support the barbel (see below). In the midline, each half of the muscle joins in a raphe which, in turn, is attached by strong connective tissue to an overlying collar of fatty tissue (ft, Fig. 11C). This collar encircles the leading edge of the antero- and dorsohyals and covers the basihyal.

Only in some pimelodid taxa is there such a complex arrangement of the hyoid musculature as in Hypophthalmus. In Pimelodus, Sorubim and Pseudoplatystoma the protractor hyoidei is complexly aponeurotic, and for its greater part is attached to the large 


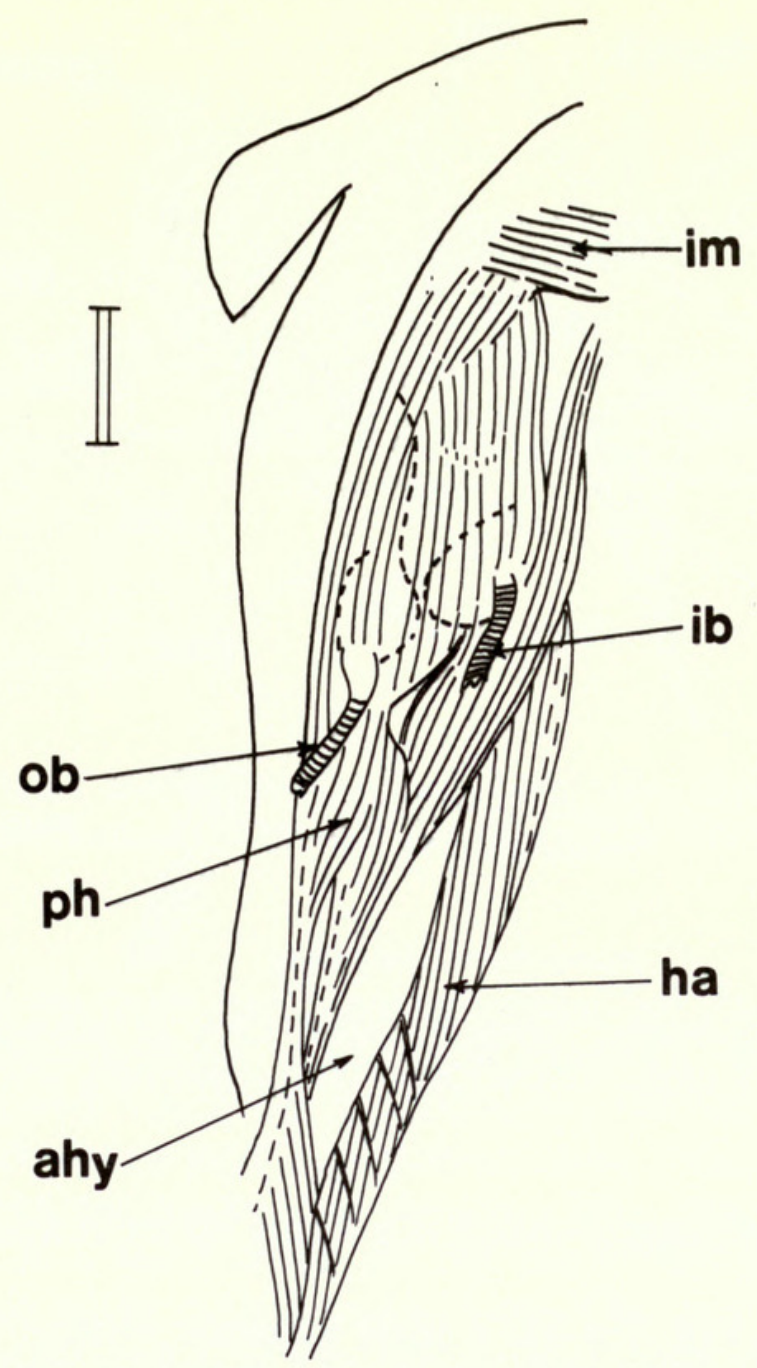

Fig. 12 Sorubim lima; ventral view of hyoid musculature (dashed lines=outlines of barbel supporting plates. Drawn from specimen BMNH 1969.7.15.26. Scale $=5 \mathrm{~mm}$. ib, ob $=$ inner and outer mandibular barbels.

cartilaginous plates supporting the bases of the barbels (Fig. 12). Ghiot (1978) distinguished in Pimelodus clarias five separate sections of what he termed the superior hyoidian protractor muscle in addition to separate lateral and medial divisions. The complexity of the hyoid musculature with separate mandibular barbel muscles attached to basal cartilages appears to be derived for at least one group of pimelodids and the Hypophthalmidae. The usual condition in siluroids is for the mandibular barbels to be 'embedded' within the protractor hyoidei, with bundles of fibres inserting on the anterior and posterior bases of the barbels and performing the function of retractors and protractors. This arrangement of hyoid musculature is illustrated by Singh (1967) in Bagridae and Winterbottom (1974, fig. 12) in Ictaluridae.

Unlike other otophysans, the siluroids exhibit considerable variability in the morphology of the hyoid musculature. A comparative study of these various arrangements appears to offer a fruitful field of potential synapomorphies.

\section{The snout and jaws (figs 11-15)}

Ramsay Wright's (1885) description of the snout region in Hypophthalmus can hardly be bettered and the following account is merely a supplement.

The entire ethmoid region is of papyraceous bone interspersed with cartilaginous strips (ec). Such cartilaginous areas separate the ethmoid (eth) from the lateral ethmoids and are bridged by the spine-like nasal bones (na, Fig. 13A). It is not possible to determine whether the ethmoid bone is a supra- or a mesethmoid. That it is so thin, and its lateral and posterior 


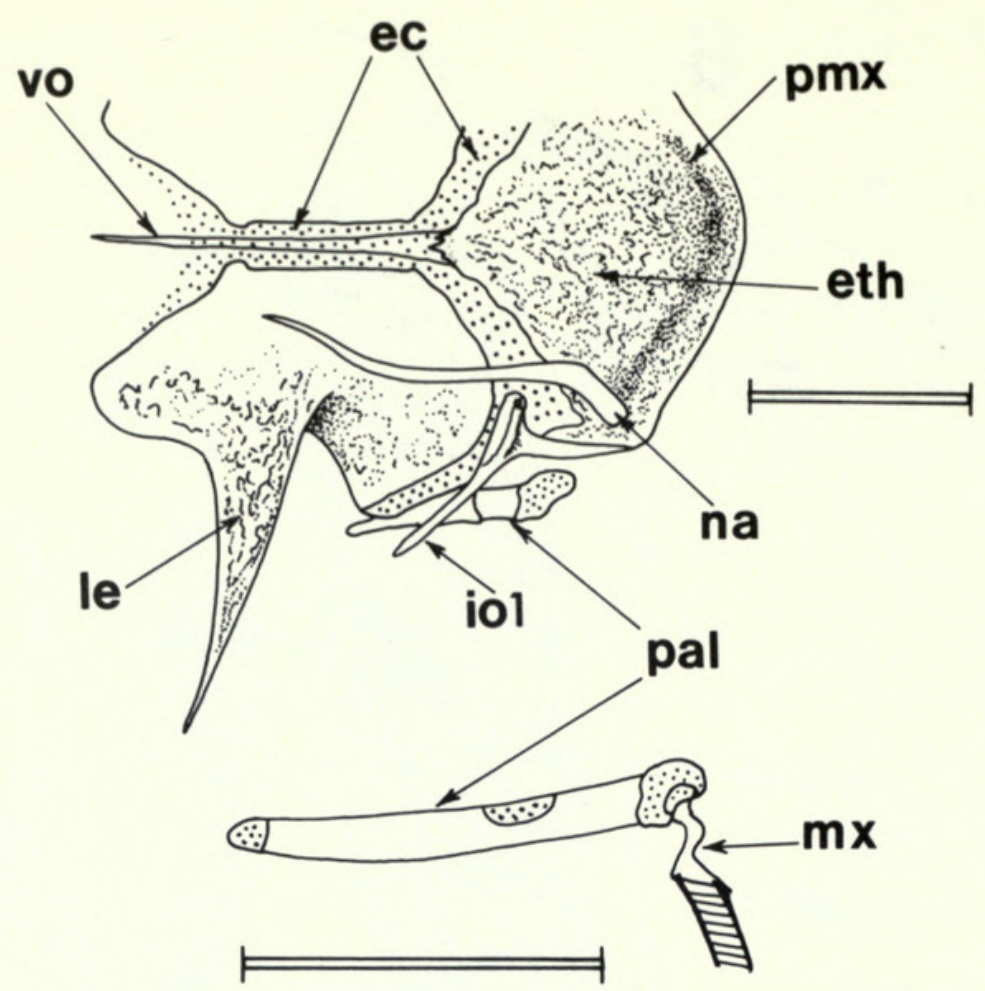

Fig. 13 Hypophthalmus edentatus; (upper) dorsal view of ethmoid region, (lower) palatinemaxillary articulation. Scales $=5 \mathrm{~mm}$. Drawn from specimen BMNH 1972.7.27: 675-678.

margins grade into cartilage suggest that it is a single element and is entirely mesethmoidal in origin.

The lateral ethmoid (le, Fig. 13) has a wide anterior surface with a convex antero-lateral margin; postero-laterally its border is produced into a long, ventrally directed spine which almost meets the third infraorbital. The medial border of each lateral ethmoid abuts the midline mesethmoidal cartilage. The vomer is needle-like, its head slightly broadened and resting below the ethmoid (v, Fig. 13).

The nostril is bordered medially and laterally by the anterior arm of the bifurcated $1 \mathrm{st}$ infraorbital.

The edentulous premaxillaries (pmx, Fig. 13) are barely identifiable as separate elements, being fused with the ethmoid and distinguishable only by their denser ossification. They are so firmly united at the symphysis that even under a magnification of $50 \times$ a suture is not visible in alizarin preparations. The maxilla is a small, well-ossified, flattened and hookshaped bone (mx, Fig. 13). The blade of the hook supports the barbel (bmx), its base is rounded and articulates withe the cartilaginous tip of the palatine.

The rod-like palatine ( $\mathrm{pal}$ ) is ossified, apart from its anterior and posterior tips and a small medial disc at about its midpoint (Fig. 13). This disc articulates with the lateral border of the lateral ethmoid.

Like the upper jaw, the lower jaw is also edentulous. The dentary (d) contributes to half the length of the mandible and is strongly sutured to the anguloarticular (aa).

The coronoid process is formed largely by a dorsal extension of the Meckelian cartilage (com, Fig. 14). The horizontal segment of this cartilage extends anteriorly along the medial face of the dentary and also has a slight posterior extension. The mandibularis nerve passes across the medial face of the upright part of the cartilage and then between the horizontal segment and the dentary wall. The nerve trunk continues along the ventral rim of the dentary and then bifurcates, each ramus inserting into the base of a corresponding mandibular barbel. A separate rod-like cartilaginous element lies antero-dorsally to the coronoid cartilage (cr, Fig. 14). Its distal tip is forked, and attaches to the lateral fold of thick labial tissue. The cartilage is mobile. When the jaws are abducted, and the labial tissue made taught, the cartilaginous rod rises to an acute angle. 


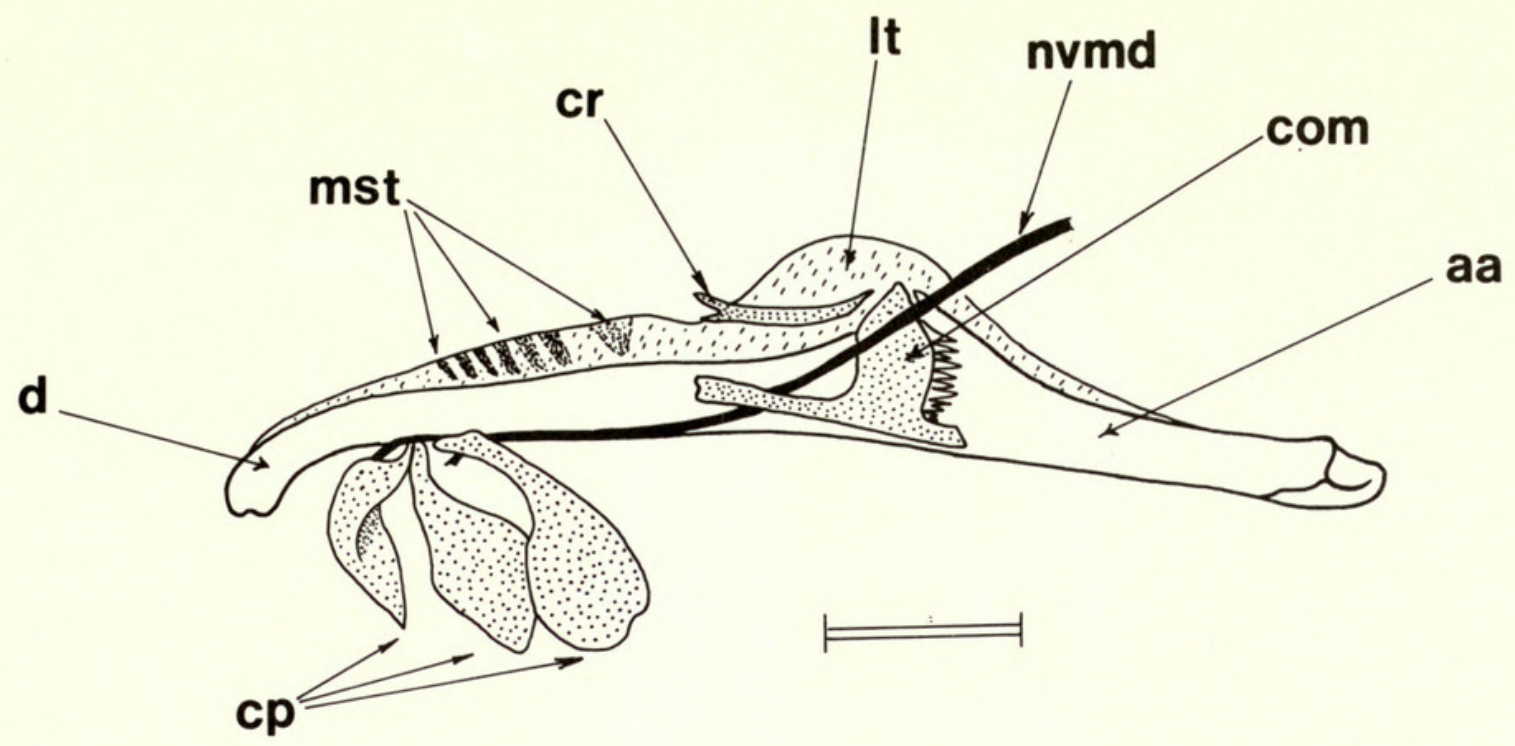

Fig. 14 Hypophthalmus edentatus, lower jaw (right) in medial view. Drawn from specimen BMNH 1972.7.27: $675-678$. Scale $=5 \mathrm{~cm}$. com $=$ coronoid process of Meckelian cartilage; $l \mathrm{t}=$ labial tissue.

The barbels are supported on three cartilaginous plates (cp, Figs 11B \& 14). The first, i.e. the element closest to the jaw symphysis, is the most complex. Its flat proximal tip attaches to the dentary rim and is curved where the mandibularis branch passes between it and the dentary. The cartilage extends dorso-posteriorly as an open cylinder, its distal tip providing the insertion site for the intermandibularis muscle. The root of the inner barbel (ib) bifurcates, one part ending as a short hook on the outer part of the cartilage, the other extending along the outer side of the cylindrical section. The two inner plates are irregularly shaped. The 2nd, middle, plate contacts the symphysial plate dorsally; the 3rd, outer, is notched at its articulation with the dentary thus allowing transmission of the mandibular nerve branch to the outer barbel (ob). As with the inner barbel the outer one is also bifurcated, its thicker leg attaching to the 3rd plate, its inner, thinner leg becoming 'cartilaginous' and extending posteriorly to join the centre of the 2 nd cartilaginous plate.

Uniquely amongst siluroids, the anterior portions of the ceratobranchials enter the floor of the mouth and are curved upward, with the result that the basihyal is raised to the level of the roof of the mouth and the dorsohyals touch the underside of the ethmoid. The elevation of the floor of the mouth appears to be accomplished by the upward rotation of the medial cartilaginous plates supporting the intermandibularis muscle (see p. 16). The intermandibularis thus forms a hillock against the underside of the ethmoid and the thin upper lip tightly embraces the lower jaw when the mouth closes. The pressure created by the floor rising against the roof of the mouth serves to force water through the mesh-like gill-rakers which filter out particulate material. The length of the gill openings presumably allows a high volume of water to pass rapidly over the gill-arches.

The skin covering the dentary contains 7-8 transverse tubes (mst, Fig. 14) filled with a jelly-like substance staining intensely with the mucus-specific stain alcian blue. Of the taxa examined Iheringichthys has a similar jelly-like material in the lower lip, but it is concentrated in ampullae in the tissue close to the jaw symphysis and not arranged in widely spaced rows. Gelinek (1978) has described ampullary organs in the epidermis of Sorubim. $\mathrm{He}$ found them to be densely grouped in the labial tissue of the upper jaw and noted their structural similarity to those organs in Plotosus. Gelinek observed the similarities between these organs to those of gymnotids and mormyrids, thus hypothesising a similar function, namely electroreception.

\section{The snout and jaws in other siluroids}

The presumed plesiomorph condition of the ethmoid in siluroids is that which occurs in 

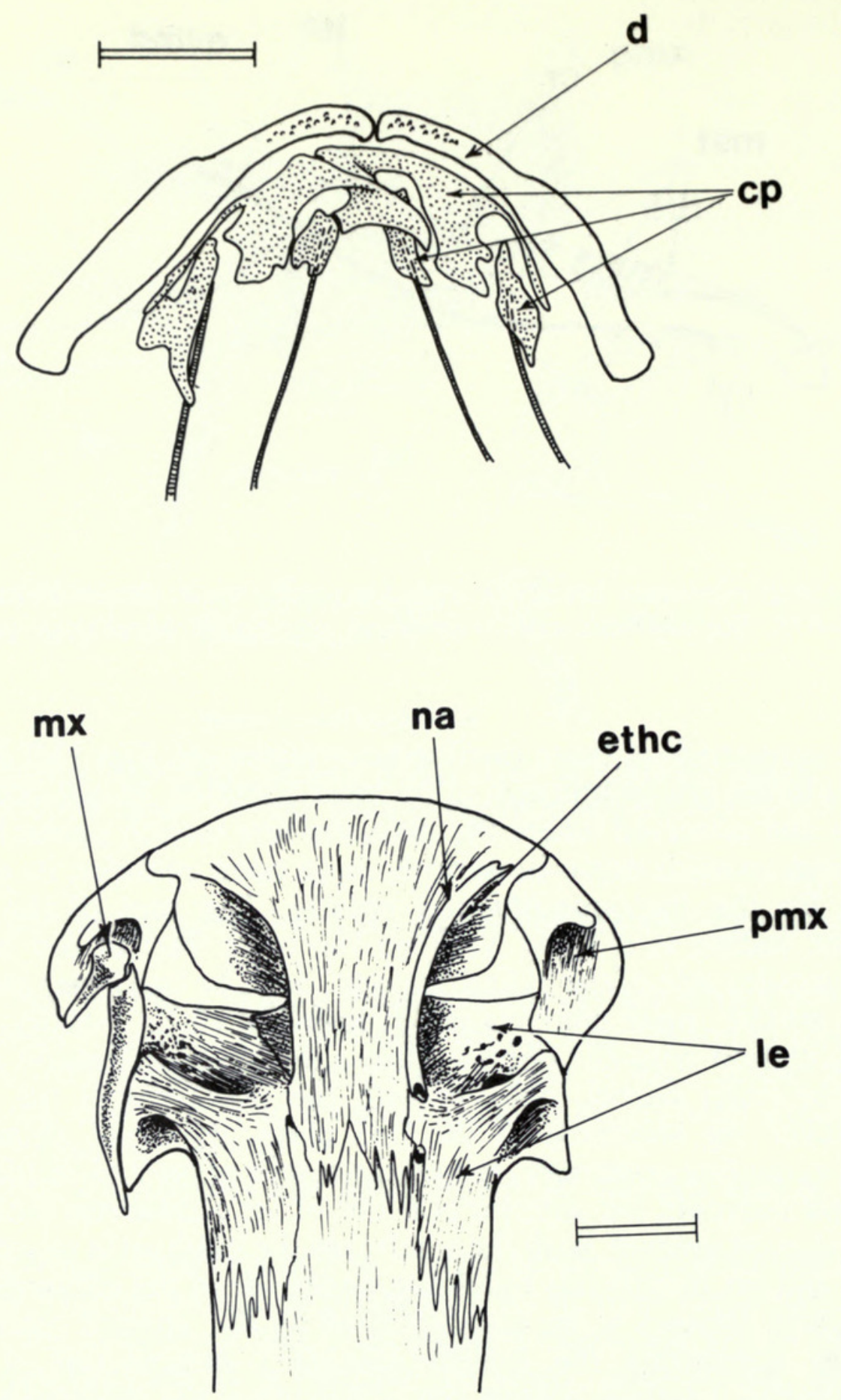

Fig. 15 Upper, Iheringichthys labrosus, ventral view of mandibular barbel supporting elements. Specimen BMNH 1934.8.20: 70-72. Scale =2 mm. Lower, Luciopimelodus pati, dorsal view of ethmoid region. Specimen BMNH 1878.5.16: 30 (dry skeleton). Scale $=3 \mathrm{~mm}$. $d=$ dentary.

many taxa belonging to the Diplomystidae, Trichomycteridae, Bagridae, Ictaluridae, Pimelodidae, Mochokidae, Plotosidae and Loricariidae, here the ethmoid is elongate and Tshaped and often with a median anterior notch (see Fink \& Fink, 1981). Howes (1980) mistakenly considered this type of ethmoid in Mochokidae as apomorphic.

In its presumed plesiomorph condition, the siluroid lateral ethmoid is triangular, closely united with the parasphenoid ventromedially and with the orbitosphenoid posteriorly.

The expanded and poorly ossified ethmoid region of Hypophthalmus is considered to be a derived condition. Other derived states of the ethmoid are those where the bone is flattened with divergent anterior forks (Ageniosidae) is curved ventrally (some Ariidae) or is cavitous with a medially grooved surface (some Auchenipteridae). Another derived form occurs in one group of Pimeloididae, Piramutana, Hemisorubim, Luciopimelodus, Brachyplatystoma, Pseudoplatystoma and Sorubimichthys. Here the mesethmoid is greatly depressed and 


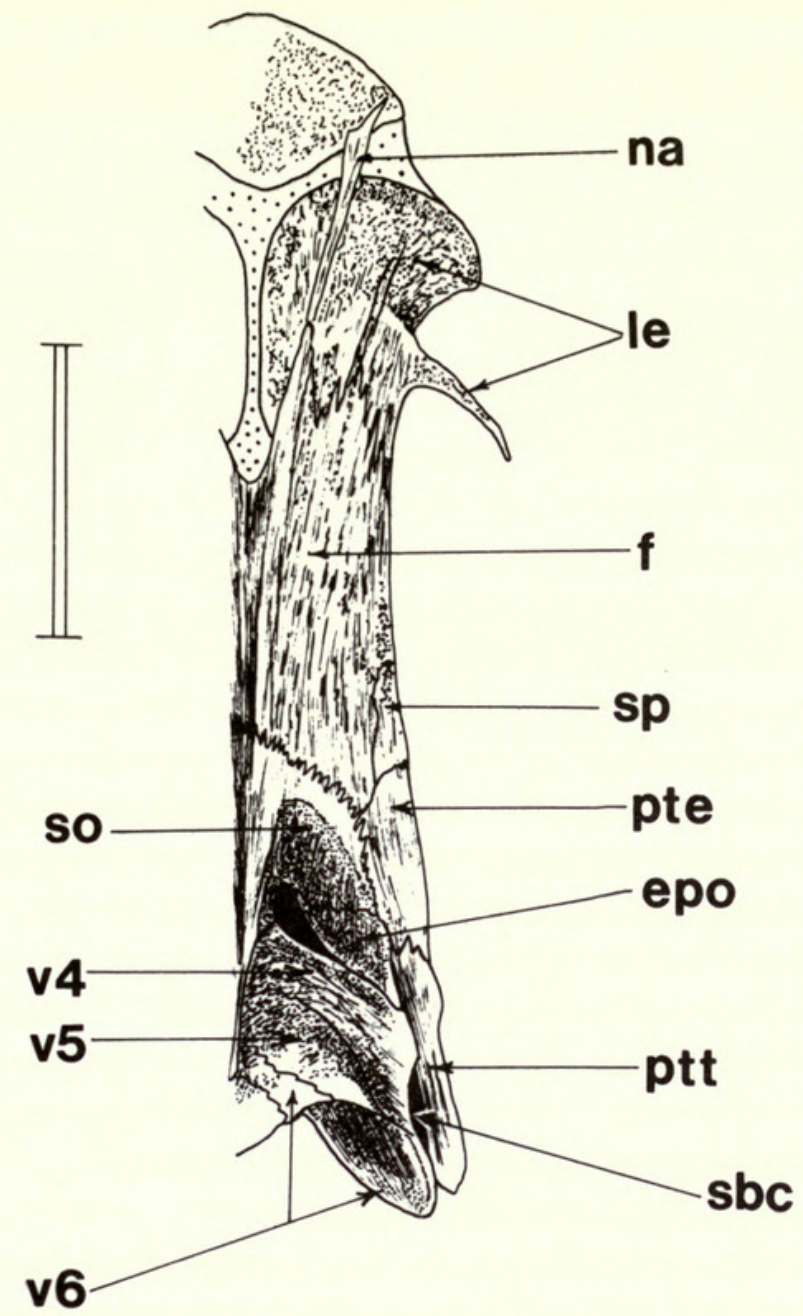

Fig. 16 Hypophthalmus edentatus, dorsal view of cranium. Specimen BMNH 1972.7.27: 675-678 (alizarin). Scale $=10 \mathrm{~mm}$.

expanded laterally (Fig. 15). As in Hypophthalmus the lateral portion of the ethmoid forms a large cavity wherein lies the olfactory organ (etch, Fig. 15).

Derived conditions of the lateral ethmoid are those where the bone has a posterior process contacting an anterior process of the frontal (some Ariidae and Pangasiidae) and where the bone is extensive, its antero-lateral portion lamellate, extensively cancellous and vacuolate. This latter condition occurs in Pangasiidae, Amphiliidae, Auchenipteridae and Pimelodidae, but among the latter family only one taxon, Parapimelodus, approaches Hypophthalmus in the width and shape of its mouth.

The mandibular barbels of pimelodids are particularly well-developed and in some taxa, as in Hypophthalmus, they articulate with large cartilaginous plates, e.g. Sorubim, Pseudoplatystoma, Iheringichthys, Pinirampus, Pimelodus (part), Luciopimelodus. The two former genera differ from Hypophthalmus, however, in having the barbel origin remote from the jaw symphysis. Ghiot (1978) described the cartilaginous plates in Pimelodus 'clarias' and commented on the elasticity of the plates and their function of supporting and moving the barbels. In Pimelodus blochii, Iheringichthys, Pinirampus and Luciopimelodus the barbels lie close to the symphysis, the presumed plesiomorph condition, but the cartilaginous supporting plates have a complex form resembling that in Hypophthalmus (Fig. 15). These taxa also share with Hypophthalmus the peculiar mandibular sesamoid cartilage which supports the lip fold, and the coronoid extension of the Meckelian cartilage (see p. 18 above).

The cranium (Figs 16-18)

There is little purpose in presenting a detailed description of the cranium, already described 
by Wright (1885). It is necessary only to comment on those features pertinent to the present discussion.

The neurocranium is moderately broad, transversly convex, becoming high-vaulted in the occipital region, and has a deep supraoccipital crest (Fig. 16). All the cranial bones are of a honeycomb texture with the frontal papyraceous. Nearly all sutures are synchondral, and fatty tissue pervades bone-muscle interspaces.

\section{The otic region}

The prootic is pierced by two foramina (pro, Fig. 17). The hyomandibular and palatine branches of the VII cranial nerve emerge through the posterior one (fhvii) whilst the oculomotor, trigeminal, abducens and facial nerves emerge through the anterior foramen in the border of the bone (ftf).

In almost all siluroids investigated there is but a single foramen piercing or indenting the prootic. In some ariid taxa the prootic is imperforate and the foramen for the cranial nerves is contained within the pterosphenoid. The absence of a second, posterior, opening in the prootic of most siluroids is due to the peculiarity of the cranial blood vascular system in these fishes. In the majority of teleosts the posterior prootic foramen serves for the passage of the jugular vein (lateral head vein) as well as the hyomandibularis nerve trunk. In siluroids, the jugular lies lateral to the cranial wall and is joined by its various branches in the same aperture as that through which the trigeminal nerve complex passes.

The absence of a complete trigemino-facialis chamber in siluroids has been commented upon by several authors as the following quotations indicate:

Allis (1908:259) referring to Ictalurus (=Amiurus) notes that, 'The artery (external carotid) does not apparently traverse a trigemino-facialis chamber, for although it would seem as if this chamber must be present in some form, there is no proper indication of but one cranial wall in this region, and that one wall would seem to be the inner wall of the chamber; for both the external carotid and the jugular vein lie external to it.'

De Beer (1937:137) again in referring to Ictalurus comments, 'There is no lateral commissure or pila antotica. The side wall of the skull in the orbital region therefore presents a continuous fontanelle-the sphenoid fontanelle-between the hind edge of the preoptic root of the orbital cartilage and the anterior basicapsular commissure. ..'

Bamford $(1948: 365,367)$ referring to Galeichthys, 'The normal foramina for the exit of the various parts of V and VII are absent, and the exit of these is limited to the sphenoid fissures.' ...'There is no trace of a pila lateralis or any similar structure.'

Alexander (1965:95) finds that in siluroids, 'The chondrocranium lacks the lateral commissure. The trigemino-facialis chamber of the adult skull has consequently lost its walls.'

All these authors are agreed that the siluroid condition is one where the trigemino-facialis chamber has been modified and the prefacial commissure suppressed. Bamford (1948) suggested that cartilaginous growth from the anterior edge of the otic capsule had crowded the nerves and vessels into the same foramen as the optic nerve (see below concerning the passage of the optic nerve).

The absence or reduction of an internal carotid artery in certain siluroids has also been the subject of comment by Allis (1908), Goodrich (1930), De Beer (1937) and Bamford (1948). According to Bamford (1948) the internal carotid has all but disappeared, with a consequent modification of the arterial circuitry. As yet, too few siluroids have been examined to ascertain the extent of this specialization.

\section{The optic foramen and the suprasphenoid}

In Hypophthalmus passage of the optic nerve (II) is through a separate foramen between the pterosphenoid (pts) and the 'suprasphenoid' (see below). In many siluroids there is no separate optic foramen, the optic nerve sharing the same opening as the trigemino-facialis 


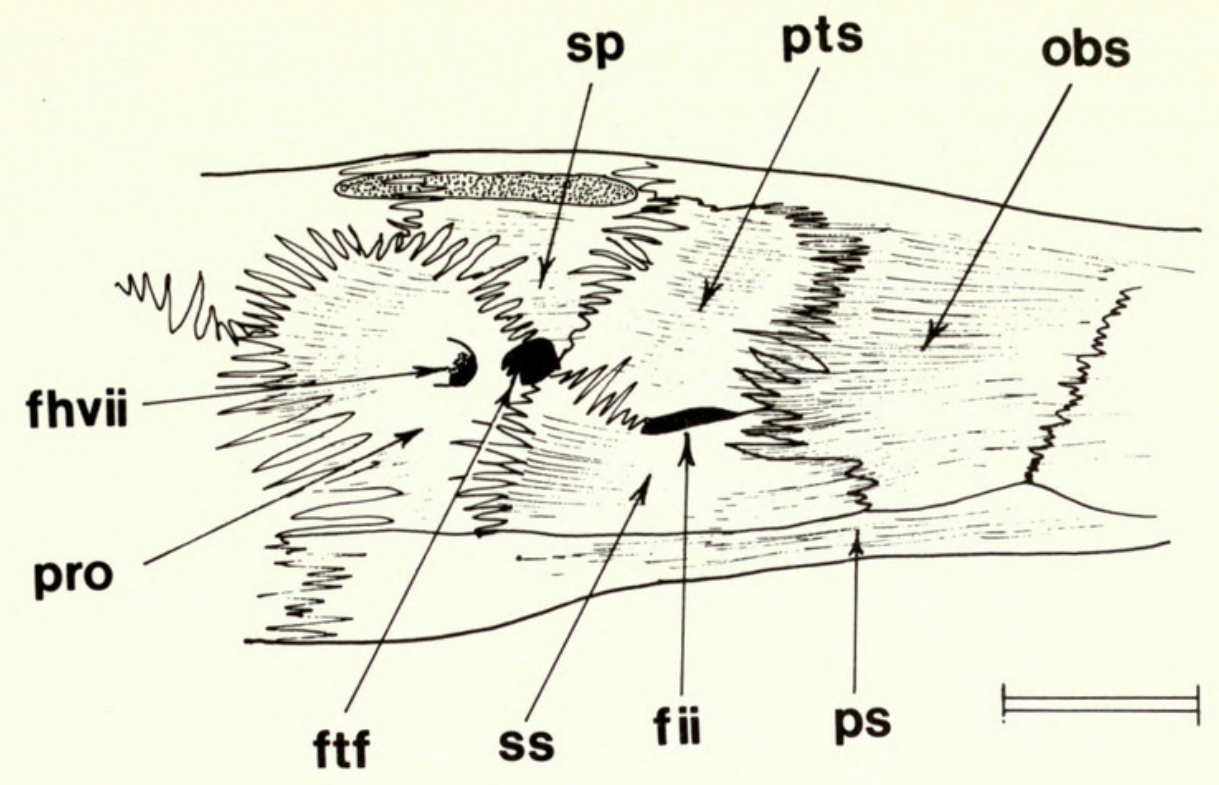

ftf
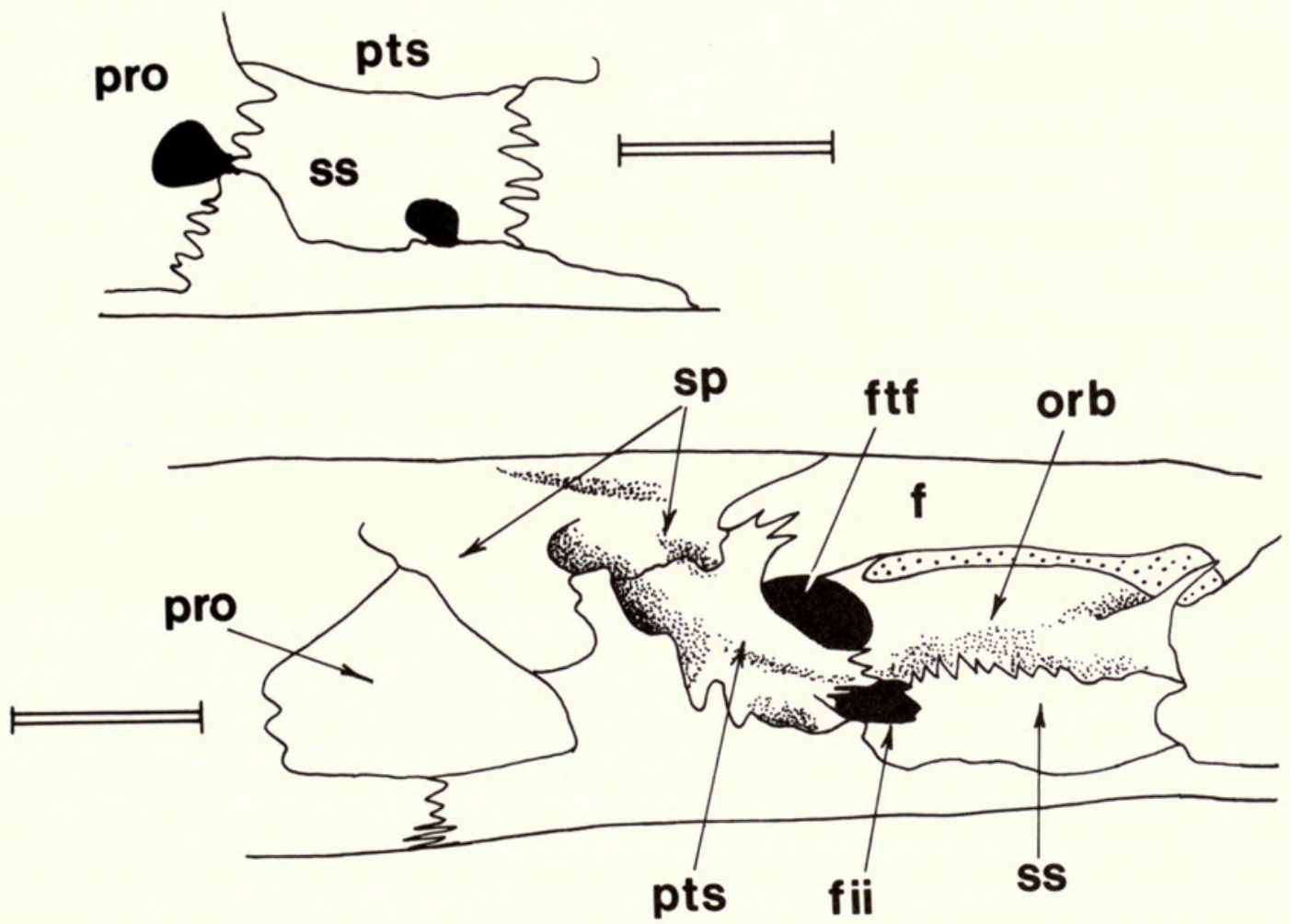

Fig. 17 Neurocranium, otic region of: (upper) Hypophthalmus edentatus ventro-lateral view. Specimen BMNH 1972.7.27: 675 (alizarin). Scale $=3 \mathrm{~mm}$. (centre) Auchenipterus nigripinnis lateral view. Specimen BMNH 1910.5.26: 12 (skeleton). Scale $=3 \mathrm{~mm}$. (bottom) Pterodoras granulosus lateral view. Uncatalogued skeleton. Scale $=10 \mathrm{~mm}$. $\mathrm{ss}=$ suprasphenoid.

complex, e.g. Diplomystidae, Callichthyidae, Siluridae, Bagridae (part), Clariidae. It is more usual in siluroids for there to be a separate foramen for the optic nerve between the pterosphenoid and parasphenoid or the suprasphenoid.

Wright (1885) referred to a paired element in Hypophthalmus as a basisphenoid. The bone in question is long and shallow and contacts the pterosphenoid, orbitosphenoid and prootic (ss, Fig. 17). Between it and the pterosphenoid is a slit-like foramen through which passes the optic nerve (fii, Fig. 17). In many taxa I have examined a similar element is present, and in the Auchenipteridae and Doradidae it is pierced by the optic foramen (Fig. 17), a feature recognised as synapomorphic. 


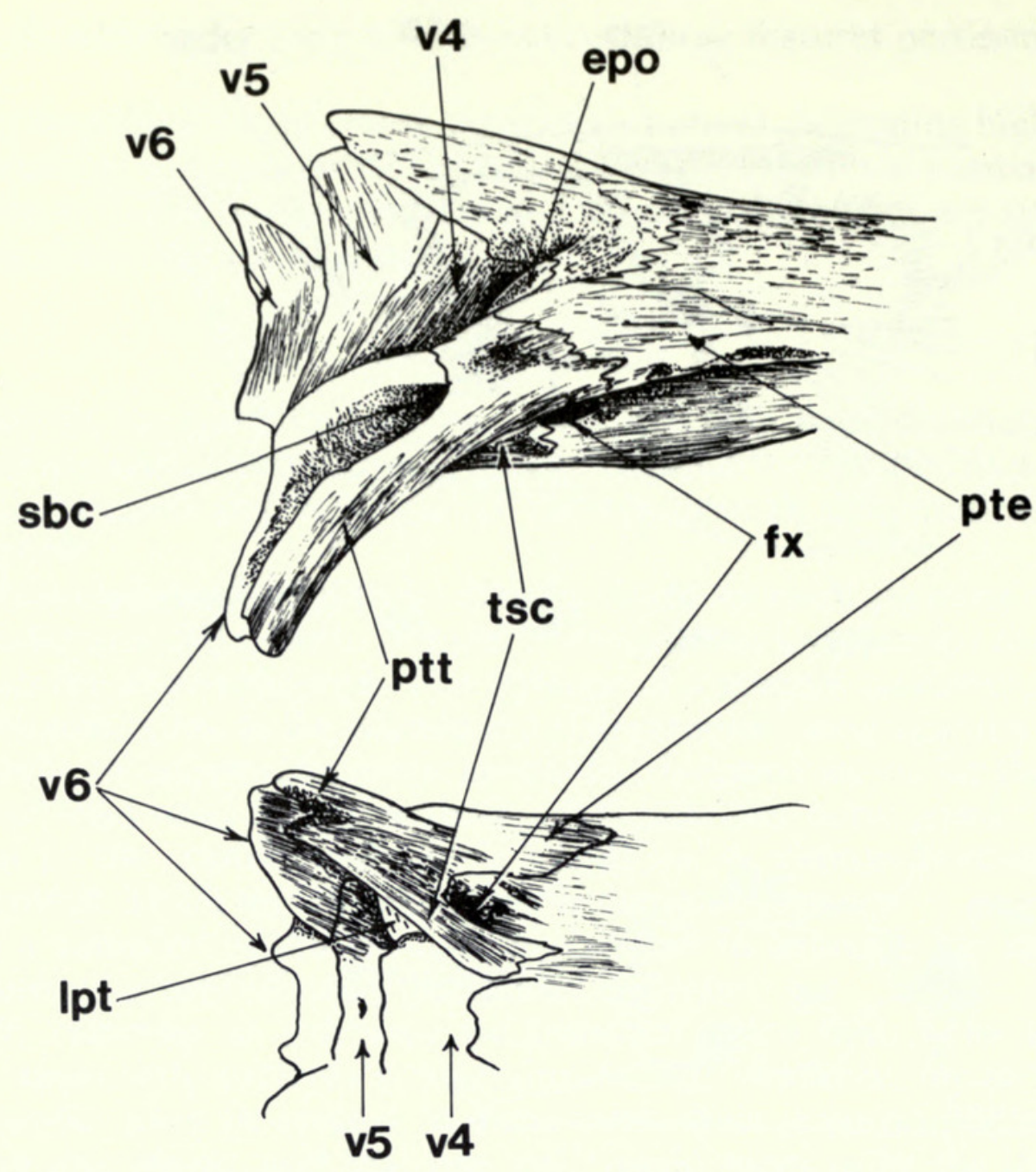

Fig. 18 Hypophthalmus edentatus neurocranium, occipital region (upper) in lateral, and (lower) in ventral views. Composite drawing from alizarin and dry preparations. tsc $=$ 'transcapular'.

McMurrich (1884a) and Kindred (1919) have described the so-called basisphenoid in Ictalurus (=Amiurus). Kindred (1919: 39-40) discussed the homology of this element and decided that the term 'suprasphenoid' rather than basisphenoid would be better applied to it. He defined the suprasphenoid as a '. . . connective tissue ossification above the parasphenoid and between the ventral ends of the alisphenoids (=pterosphenoids).' Daget (1964) also advocates caution in applying the term 'basisphenoid' to this element in siluroids. Thus, Kindred's term, suprasphenoid is adopted here as one being free of any implied homology.

The homology of the siluroid parasphenoid itself is in doubt. Allis (1919) considered the problem in Ictalurus, (=Amiurus) and argued that the siluroid parasphenoid was an ossification of the ventral myodome roof, the posterior myodome being absent in siluroids.

Bamford (1948:375) remarks that in Ictalurus, ‘. . there are so many exceptional features in this region of the skull ... myodome basicranial relations, absence of trigemino-facialis chamber, blood systems, pilae etc-that the matter cannot be regarded as settled.'

Until more is known about the occurrence of the suprasphenoid amongst siluroids, and until more definite information on its ontogeny and relationships with other elements is available, the value of this bone as a taxonomic character cannot be determined.

\section{The occipital region}

There are several outstanding features in this region of the cranium in Hypophthalmus, not least of which is the ankylosis of the skull and the vertebral column (Fig. 18). 
The supraoccipital (so) crest is high and posteriorly is firmly united with the succeeding neural spine (4th). Anteriorly the supraoccipital meets the frontal (f), and laterally it is bounded by the epioccipitals. Wright's (1885) description and figure give an incorrect shape to the supraoccipital, and those elements bounding it are misidentified.

Posteriorly the epioccipital (epo) is separated from the parapophysis of the 4th vertebrae by an elliptical foramen through which passes the ramus lateralis (Fig. 16). This foramen is shown in Wright's (1885) figures (fe, figs $1 \& 3$ ), but in the wrong position, as lying between the pterotic and posttemporal.

The 'posttemporal' is an extensive bone (ptt, Fig. 18), its anterior part meeting the pterotic (pte) and exoccipital (exo) and its medial margin bordering the parapophyses of the 4th, 5th and 6th vertebrae. In no other siluroid does the posttemporal extend so far posteriorly, nor articulate with the 6th vertebra. The ventral limb of the 'posttemporal' is broad and thick, and articulates with the basioccipital. A thick ligament runs between its upper medial border and the 4 th centrum (1 pt, Fig. 18).

There has been some considerable debate concerning the identity of the element connecting the cleithrum with the cranium in siluroids. The most recent discussions are by Lundberg (1975) and are reconsidered by Fink \& Fink (1981). The latter conclude that the siluroid element is a composite formed from the supracleithrum, possibly the posttemporal and Baudelot's ligament. That part of the element contacting the basioccipital and identified by Fink \& Fink (1981) as the ossified Baudelot's ligament was referred to by Kindred (1919) as the transcapular.

I have little to add to this discussion except to confirm Lundberg's (1975) observation that the small plate-like bone (previously thought to be an extrascapular, but identified by Lundberg as the posttemporal) does not occur in the Hypophthalmidae. However, such an element is present in Luciopimelodus which I have labelled here as an extrascapular so as to conform with Fink \& Fink's nomenclature (es, Fig. 20). Notwithstanding Lundberg's evidence (1975) from the sensory canal pattern that the posttemporal is lacking, it would seem that the supracleithrum would be the element of the clavicular series most 'easily lost' in phylogeny; see for example Rosen (1964) where the supracleithrum is lacking in certain atheriniforms.

\section{The complex vertebrae, swimbladder and posterior lateral line nerve} The complex vertebrae and swimbladder (Figs 19-21)

Both Wright (1885) and Chardon (1968) have described the peculiar nature of the Weberian apparatus in Hypophthalmus. The most notable character is the complex encapsulation of the swimbladder formed of the parapophyses of the 4th centrum. The parapophyses are produced into dorsal and ventral laminae, the ventral lamina formed partly from superficial ossification; see below p. 28 . The cavity so formed provides a capsule housing the swimbladder (sbc, Fig. 18).

Internally the swimbladder (sb, Fig. 19) is divided by a longitudinal septum. Externally it has a thick tunica externa but no tunica interna. The opening between the upper and lower parts of the parapophysis together with the lateral extension of the 'posttemporal' form a funnel-like aperture to the exposed outer wall of the swimbladder (Fig. 19). No transverse duct connects the swimbladder chambers.

The tripus (tr) is connected to the tunica externa just anterior to the septum. A medial extension of the tripus articulates with the complex vertebrae (3rd centrum). Anteriorly the tripus contacts the scaphium (sc) via a minute intercalarium (ic). The claustrum is lacking. The scaphia provide the walls of the cavum sinus imparis. According to Wright (1885:114), the roof of the cavum sinus imparis is an ossified plate of dura mater attached to the first centrum, but in the preparations examined it seems as if the roof is just a continuation of the exoccipital. The 1 st centrum is so far forward that it lies between the exoccipitals and above the basioccipital (v1 + 2, Fig. 19). 
Wright (1885) maintained that the Weberian apparatus in Hypophthalmus has been '...pushed (in the process of its reduction) into the foramen magnum, instead of being outside the skull... A Although that author considered the Weberian apparatus and swimbladder to be functionless (a theory endorsed by Bamford, 1948) this does not appear to be so. The swimbladder is constructed as in other siluroids and there is a mobile articulation of the Weberian ossicles, all of which suggests that the system is functional (see below).

\section{The complex vertebrae and swimbladder in other siluroids}

In siluroids, as in other otophysans, the anterior four vertebrae are modified to form the Weberian apparatus. However, unlike other otophysans, there is a greater degree of fusion between the centra involved, and the united elements are usually referred to as the complex vertebrae (Chardon, 1968). In addition to this fusion of the first four centra, sometimes the 5 th, and more rarely the 6 th, 7 th and even 8 th are also incorporated in this complex.

The lateral processes of the various centra incorporated in the complex vertebrae are always well-developed, often forming sheets of bone which may contact one another to provide a dorsal shield to the swimbladder. The anterior ramus of the 4th vertebral parapophysis (following Tavolga, 1962, referred to hereafter as the Müllerian ramus) may contact the inferior limb of the 'posttemporal' and, in some taxa where the swimbladder is encapsuled, it may form a substantial part of the capsule. Alternatively, the Müllerian ramus may remain free from the 'posttemporal' and curve ventrally to contact the tunica externa of the swimbladder.

In some families (Doradidae, Auchenipteridae, Mochokidae, Malapteruridae, Pangasiidae, Ariidae) the Müllerian ramus is free from any attachment with the 'posttemporal', its distal tip is expanded into a plate which contacts the tunica externa of the swimbladder. Protractor muscles run from the bony expansion to the cranium and neural spine complex supporting the dorsal fin. Müller (1842) named this mechanism the Springfederapparat, now usually referred to as the elastic spring apparatus, and below as the ESA.

The plesiomorph condition of the swimbladder in siluroids is assumed to be one in which

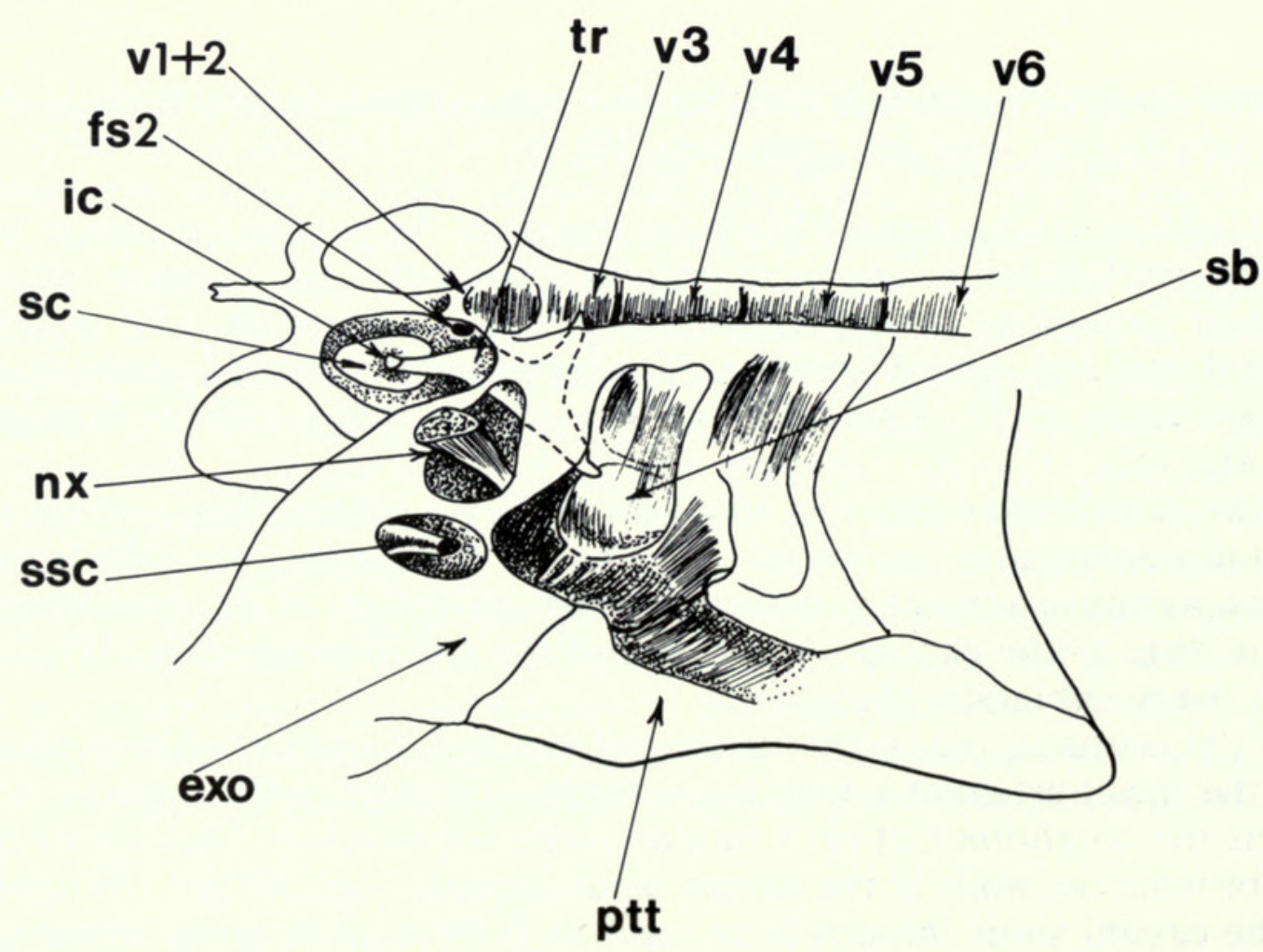

Fig. 19 Hypophthalmus edentatus swimbladder and Weberian apparatus. Dorso-lateral view of transverse section through the anterior vertebrae and occipital region. Composite drawing from alizarin and dry preparations. fs $2=$ foramen of 2 nd spinal nerve; $s s c=$ semicircular canal. 

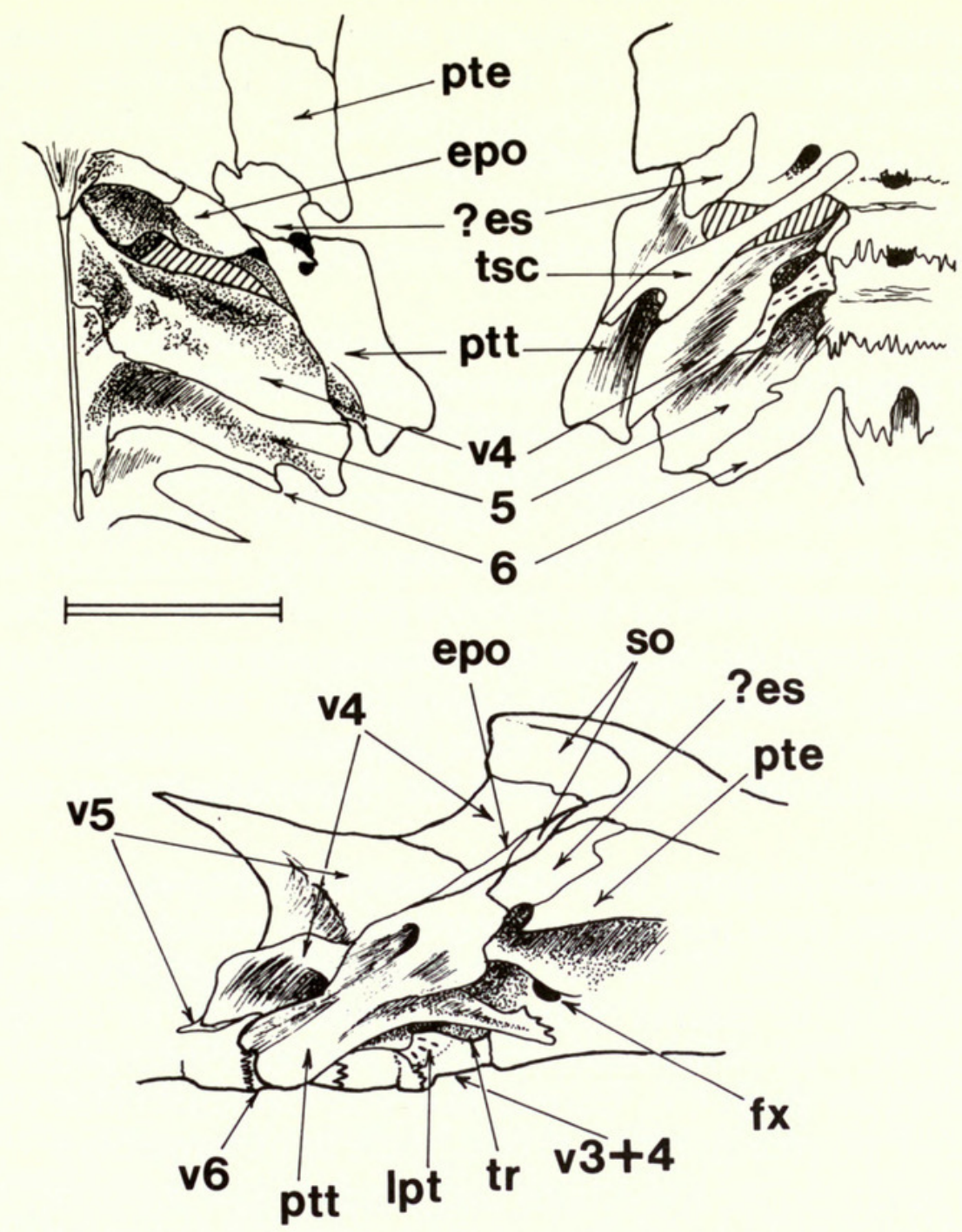

Fig. 20 Luciopimelodus pati complex vertebrae in (left) dorsal, (right) ventral, and (bottom) lateral views. Specimen BMNH 1878.5.16: 30, dry skeleton. Scale $=5 \mathrm{~mm}$.

the organ is large and free from any intimate contact with the anterior vertebral parapophyses, the lumen partially divided by a T-shaped septum, and the pneumatic duct entering the anterior transverse chamber. In taxa with this type of swimbladder, the anterior vertebrae (i.e. those following the complex vertebrae) demonstrate a range of fusion patterns, from being completely unfused, Diplomystidae, to the fusion of centra 4-6 in some Pimelodidae. In those taxa with an ESA, the swimbladder is also large and not encapsuled, but it is notable that in all ESA taxa studied the complex centra display the maximal vertebral consolidation (4-6+4-7 in some ariids). In those taxa with encapsuled swimbladders, a series of progressive anterior vertebral fusions is apparent. However, only three families have the maximal fusion of 6 centra, Loricariidae, Astroblepidae and Ageneiosidae.

If progressive fusions, namely the 4th centra with the 5 th, then fusion with 6 th and 7 th vertebrae, are taken as successively derived conditions the resulting cladogram indicates that swimbladder encapsulation has occurred independently in at least two lineages (Fig. 22). However, a more rigorous study of the individual taxa within those lineages shows incongruencies in this hypothesised phylogeny. For example, the nature of swimbladder encapsulation in the Callichthyidae, Astroblepidae and Loricariidae is virtually identical, the 'posttemporal' contributing to the lateral wall of the capsule (Alexander, 1964; 1965; Chardon, 1968). These taxa also share a derived rib structure and dermal ossification patterns (see Alexander, 1965). On the basis of vertebral fusion patterns alone, however, these families appear in different lineages. Likewise, the Ageneiosidae also appears with the Loricariidae and Astroblepidae, but the encapsulation of the swimbladder is quite different since it is derived from superficial ossification (see below). 
Further incongruencies arise in this phylogeny when the detailed structure of the ESA and the associated swimbladder are taken into account. In the Doradidae and Auchenipteridae the organisation of this system is more elaborate than that of other ESA taxa. In both families the epioccipital has long posterior processes which contact the 5th and 6th parapophyses. Such features are lacking in other ESA groups. From these observations it seems very likely that the ESA has, as in the case of swimbladder encapsulation, been achieved independently in several lineages.

Another incongruency arises if the superficial ventral ossification of the fused vertebral centra is taken into account. Superficial ossifications were described by Bridge \& Haddon (1894) as a continuous sheet of bone uniting the paired parapophyses and enclosing the cardinal veins. According to Tilak (1965:170-171) the superficial ossification is derived from the tunica externa of the swimbladder. There is much variability in development of superficial ossification. In some taxa it forms a channel or a complete tunnel enclosing the dorsal aorta. In others it contributes to the anterior part of the swimbladder capsule.

There appears to be a trend for the more derived siluroids to have reduced and encapsuled swimbladders. The most extreme forms of encapsulation and swimbladder reduction are usually encountered among those taxa with accessory respiratory devices, Clariidae, Loricariidae and Callichthyidae. In this respect the Hypophthalmidae and Ageneiosidae are exceptional.

Alexander (1964) makes the point that encapsulation of the swimbladder results '. . when the anterior parapophyses have not been correspondingly reduced'. Undoubtedly this is so, the anterior (Müllerian) ramus of the 4th parapophysis progressively curving around the swimbladder and meeting the lamina of the 5th appears to be an ontogenetically obvious process of encapsulation. The swimbladder capsule may also incorporate part of the ventral superficial ossification (see above), in Loricariidae and Callichthyidae the posterior cranial bones (epioccipital and 'posttemporal') also contribute to its formation.

Alexander (1964) advanced the hypothesis that a reduced swimbladder volume could have evolved to compensate for increased buoyancy resulting from gas held in the accessory respiratory organ. Qasin \& Hasan (1961) suggested that such gas could even be used in buoyancy control. Gee (1976) does not agree, pointing out the unlikelihood of a simultaneous reduction of swimbladder volume (SBV) and development of an accessory air breathing organ (ARO) derived from some other part of the fish's anatomy. Gee also noted that loricariids although possessing the smallest SBV lack an ARO. Gee's thesis is that the overiding factor in swimbladder reduction is directed towards a demersal existence wherein a greater variety of environments may be exploited, e.g. substrate burrowing by trichomycterids; leaf litter and bank 'burrowing' by loricariids. Some of these environments, however, tend to be hypoxic and would have demanded compensatory air breathing devices.

Reduction of SBV in Hypophthalmidae and Ageneiosidae is obviously due to different factors than those obtaining in loricariids etc, and ones related to attaining neutral, or near neutral buoyancy. Unlike Old World 'pelagic' siluroids, schilbeids, siluriids and pangasiids, whose neutral buoyancy depends on a large swimbladder, the Hypophthalmidae, and probably the Ageneiosidae, rely on a high body fat content (see p. 5). More positive assertions on the functional utility of SBV reduction can only be made in the light of detailed knowledge of swimbladder physics.

Alexander (1965) states there is no known fish in which the Weberian apparatus is a functionless vestige. However, in loricariids, callichthyids and trichomycterids the ossicles are reduced, the claustrum and intercalarium lacking (see Chardon, 1968). To what degree the absence of these elements impairs or alters the function of the Weberian system is unknown.

Bamford (1948) noted that little work had been done on the ontogeny of the siluroid Weberian apparatus as compared with that in cyprinids. There has been no redress of this situation. Bamford's implication was that the entire Weberian system could have been derived independently in siluroids. This hypothesis has still to be tested. 


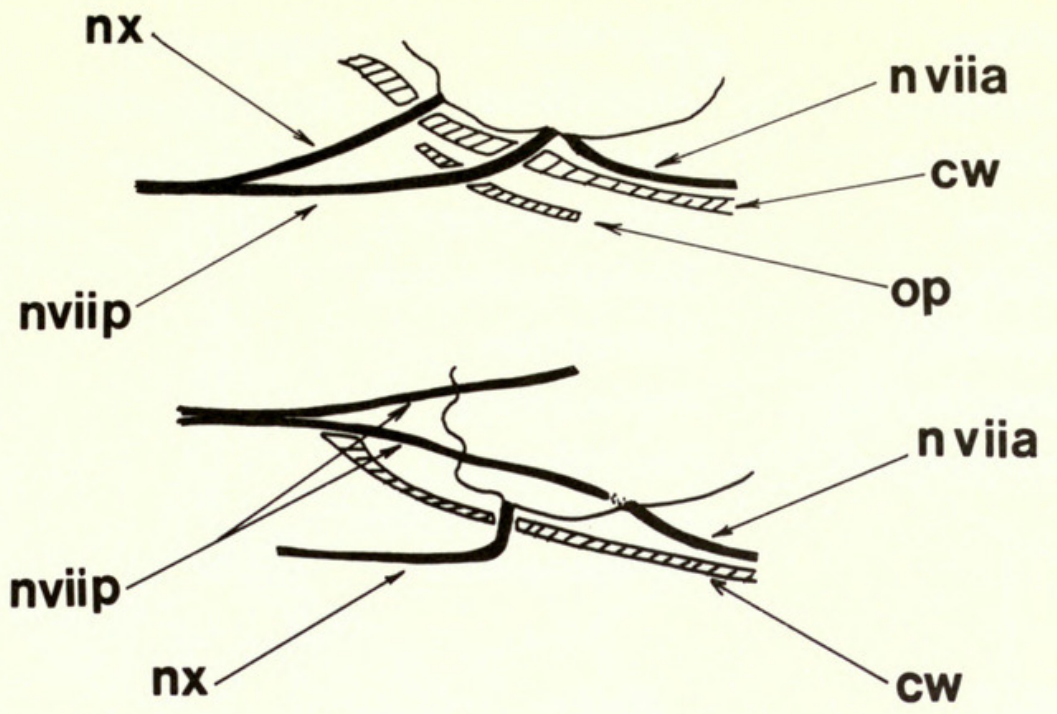

Fig. 21 Pathway of vagus and posterior branch of the facial nerves in gymnotoids (upper), and siluroids (lower). Dorsal view, semi-diagrammatic drawn from dissections of Eigenmannia virescens and Pimelodus blochii. $\mathrm{cw}=$ cranial wall; $\mathrm{op}=$ operculum.

\section{The posterior lateral line nerve}

The anterior shift and gross re-shaping of the Müllerian ramus in Hypophthalmus has necessitated a diversion in the route of the vagal ramus lateralis, posterior lateral line nerve. As a result, after leaving the exoccipital (fX. Fig. 18) it takes an almost vertical course then passes through the foramen between the Müllerian ramus and epioccipital (see above, p. 25), finally, running posteriorly across the dorsal surface of the parapophysis.

Nelson (1960) described the course of the vagus lateralis in Malapterurus as leaving the cranium and running laterally along the ossified Baudelot's ligament (inferior posttemporal limb and transcapular of authors) thence passing caudally along the length of the body; the ramus lateralis vagi of authors. Such is the usual course of the nerve in other siluroids investigated. Nelson (1960) also describes a dorsal or recurrent branch of the VII cranial nerve which, after leaving the cranium innervates the dorsal length of the body. This nerve appears to correspond with that described by Mithel (1964) as the ramus lateralis accessorius in Mystus and by Juge (1899) as the 'nerf de Weber' in Silurus.

The more direct course of the vagus lateralis in Hypophthalmus also occurs in Luciopimelodus (Fig. 20). Here too the posterior tip of the 'posttemporal' is elongated to extend as far as the 5th parapophysis, and the Müllerian ramus is elevated and strongly curved antero-ventrally to partially encapsulate the swimbladder. These features cause the nerve to follow a vertical route from its exit in the exoccipital and, as in Hypophthalmus to pass through a gap between the supraoccipital, epioccipital and Müllerian ramus (Fig. 20).

Nelson (1960) noted that in gymnotoids the '. . nerve (vagus) emerges from the posterolateral aspects of the cranium associated with the opercular muscles and passes superficial to the pectoral girdle.'; after which it penetrates the body wall musculature and follows the horizontal myoseptum.

Szabo (1974) following Nelson (1960) considers the dorsal nerve in siluroids '. . to be of the type', presumably homologous, as the lateral nerve trunk in gymnotoids. Fink \& Fink (1981) accept such a homology as a character in uniting siluroids and gymnotoids as sister groups. The very different pathways of the nerve trunk in these two groups suggests however the possibility of independent derivation.

In siluroids the vagus lateralis passes laterally across the transcapular (tsc) (Baudelot's ligament fide Fink \& Fink), over the Müllerian ramus and then ventrally, medial to the pectoral girdle. The posterior branch of the anterior lateral nerve (ramus recurvens nervi facialis; ramus dorsalis or ramus lateralis accessorium auct $t$ ) emerges through the supraoccipital to course along the dorsal aspect of the body (Fig. 21). 
G. J. HOWES

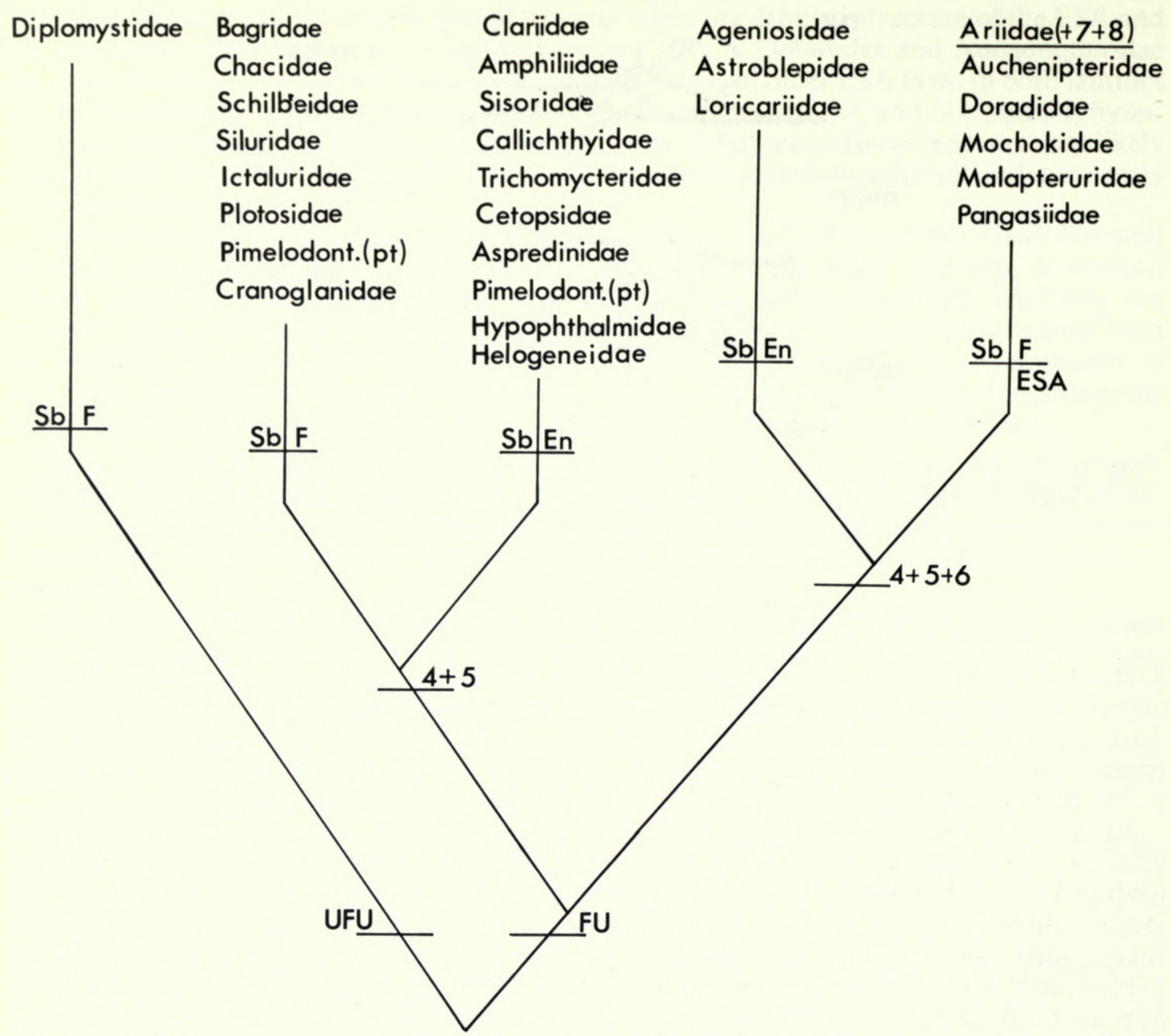

Fig. 22 Cladogram of currently recognised siluroid families based on degree of fusion of the anterior vertebrae and nature of the swimbladder. UFU =vertebrae unfused; $F U=$ vertebrae fused; $4+5+=$ numbers of centra added to the complex vertebrae; $\mathrm{SbF}=$ swimbladder free; $\mathrm{Sb}$ $\mathrm{En}=$ swimbladder encapsuled; ESA = elastic spring apparatus. For the purposes of the diagram the Clariidae includes the Heteropneustidae. The Pimelodontidae is represented on two lineages, those taxa with an encapsuled swimbladder correspond with group 1 as defined on p. 37. Ariid taxa examined appear to have the 7 th (? and 8th) centra added to the complex vertebrae. It is not certain that all ariid taxa have this many consolidated centra. Data mostly from Chardon (1968) and pers. obs.

In gymnotoids the vagus lateralis runs postero-ventrally into the epaxialis and does not pass over the 4th parapophysis. The posterior branch of the anterior lateral nerve does not pass dorsally but laterally, to pierce the hyomandibula, then to run medial to the pectoral girdle, and into the body musculature where it joins the vagus lateralis (Fig. 21).

\section{The suspensorium (Figs 23 \& 24)}

In Hypophthalmus a large pterygoid bone extends between the quadrate and hyomandibula to form a bipartite attachment with the lateral ethmoid. This articulation takes the form of a long triangular portion and an upright process (pty, Fig. 23). Between the two anterior forks a ligament runs anteriorly to attach to a minute bony element and thence to the lateral 


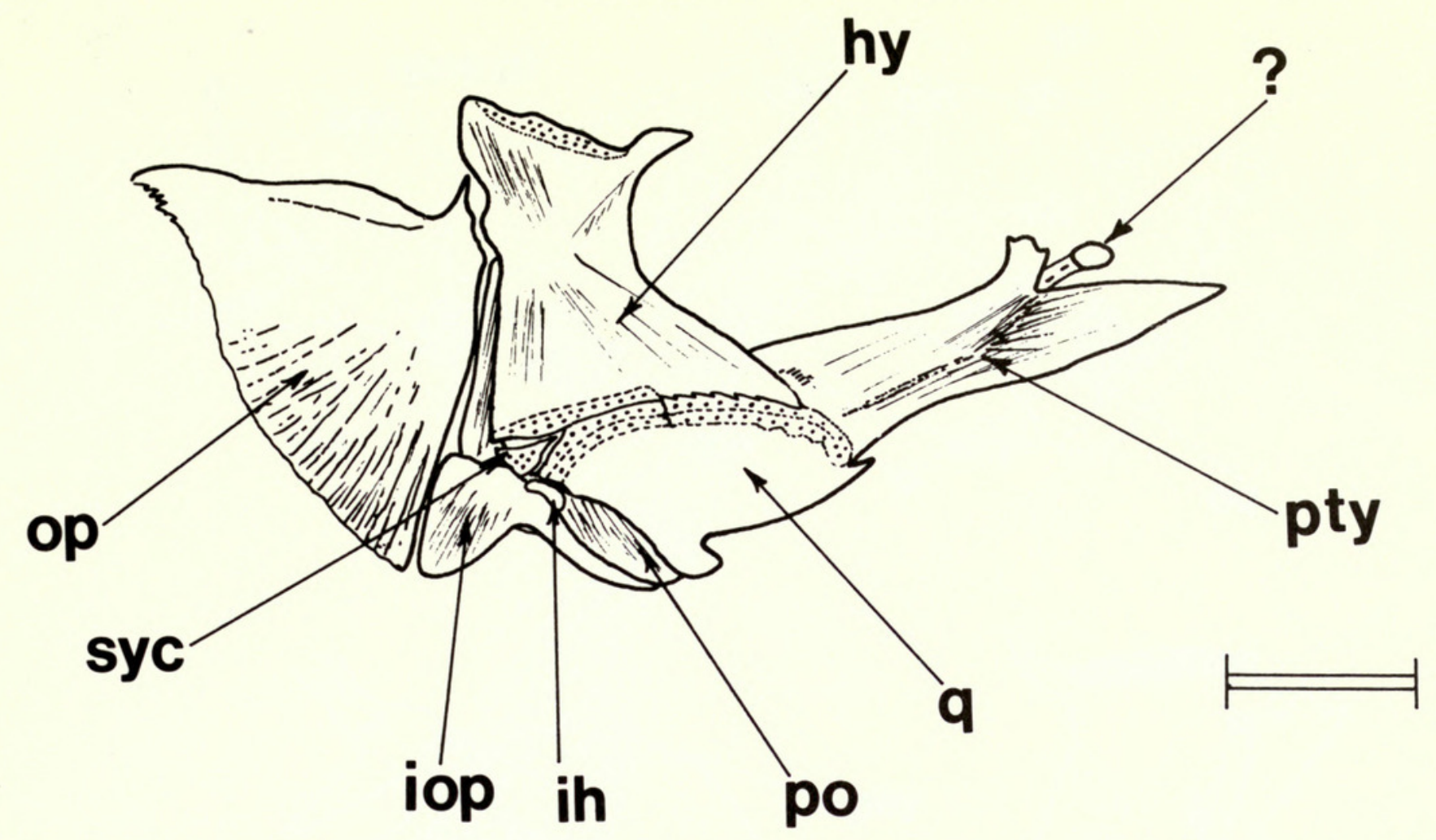

Fig. 23 Hypophthalmus edentatus suspensorial and opercular bones, medial view (cartilage dotted). Specimen BMNH 1972.7.27: 675-678. Scale $=5 \mathrm{~mm}$.

ethmoid. The pterygoid (pty, Fig. 23) contacts the quadrate synchondrally, and the hyomandibular process via a dentate suture. The hyomandibular process (hy) extends anteriorly along the dorsal rim of the quadrate (q) which it meets synchondrally. The stem shank of the hyomandibula contacts the central dorsal rim of the quadrate via a synchondrosis. Posteriorly, it is separated by a wedge of cartilage (syc), which may represent the symplectic. The interhyal (ih) articulates between this cartilaginous element, the posterodorsal edge of the quadrate, and the upper rim of the interoperculum.

The identity of the various bones comprising the suspensorium in siluroids is doubtful. Regan (1911) simply referred in pimelodids to 'pterygoids' lying between the hyomandibula and palatine. Compared with most other teleosts the pterygoid series is, for the most part, incomplete since it lacks one of the pterygoid elements usually present. Authors have been at variance as to whether it is the ecto- or endopterygoid which is absent (see comments of Kindred, 1919; Alexander, 1965 and Gosline, 1975).

The problems of identifying siluroid suspensorial elements is illustrated by reference to the pimelodid Pinirampus (Fig. 24). The pterygoid is like that of Hypophthalmus in having a sharply demarcated ventral portion that articulates with the quadrate, whilst the dorsal portion articulates with the hyomandibular process. An area of cartilage lies between the branches of the pterygoid, the hyomandibular process and the quadrate. Lying close to the anterior border of the pterygoid is a scythe-shaped bone, its elongate portion directed ventrally. The bone is connected to the pterygoid and to the lateral ethmoid via ligaments. Between the scythe-like bone and the pterygoid border is a splint-like bone which is attached by connective tissue to both the scythe-like element and the palatine.

Two identification schemes of the suspensorial elements are presented. In one (Fig. 24, left) the pterygoid is considered as the metapterygoid, the scythe-shaped bone as the endopterygoid and the splint-like bone as the ectopterygoid. In the other (Fig. 24, right) the hyomandibula plus metapterygoid are considered as forming a single element, or, alternatively the metapterygoid is considered lost, and the pterygoid as comprising the endoplus, ectopterygoid. The two isolated bones are problematical. From its position in connective tissue the splinter-like element could be a sesamoid ossification. The scytheshaped bone is characteristic of one group of pimelodids (see p. 37) and again, may be a 

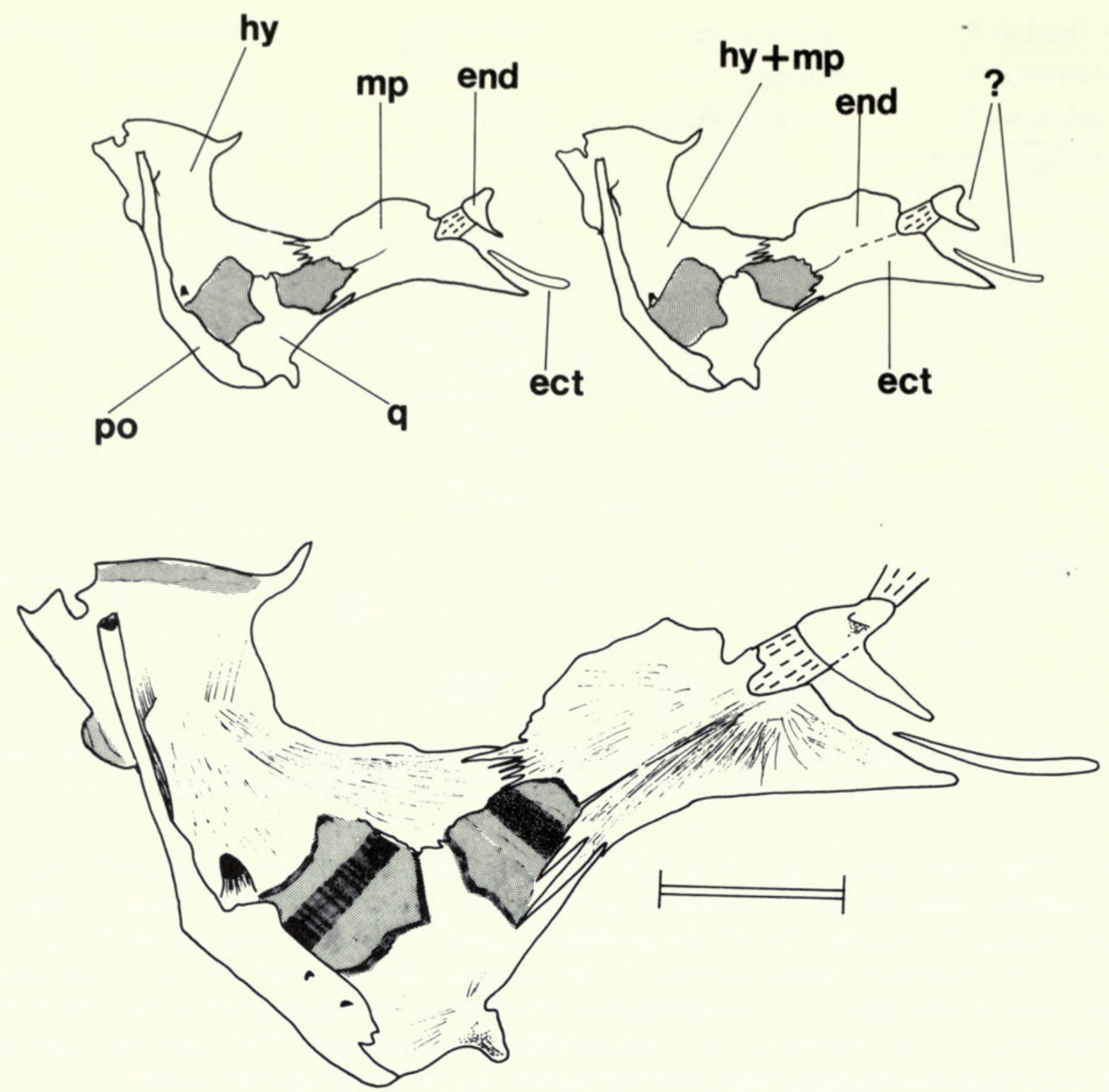

Fig. 24 Pinirampus pirinampu suspensorial and opercular (part) bones. Specimen BMNH 1934.8.20: 104-5. Scale $=3 \mathrm{~mm}$. The upper, labelled drawings represent two interpretations of the suspensorial elements. Shaded areas represent cartilage.

sesamoid bone. A small bone occurs in Hypophthalmus in a similar position and having the same ligamentous attachments as the scythe-shaped bone in Pinirampus (see above). It seems unlikely that these 'isolated' elements represent an ectopterygoid as they occur in the wrong topographical positions. The problem of suspensorial bone homologies in siluroids will be dealt with elsewhere (Banister \& Howes, in preparation).

The hyoid arch (Fig. 25)

In Hypophthalmus the anterohyal and posterohyal are exceptionally elongate and, unusually, are of equal length. The anterohyal (ahy) bears 8 branchiostegal rays (bsr) and the posterohyal (phy) 6 . The dorsal and ventral hyals $(\mathrm{dh}, \mathrm{vh})$ are small and separated from the anterohyal by cartilage. The interhyal (ih) articulates with the posterior tip of the posterohyal. The urohyal (uh) is a short oval bone lacking a medial ridge.

Gosline (1974) relates the number of branchiostegal rays to the length of the free sleeve of the branchiostegal membrane. This certainly appears to be a valid correlation in Hypophthalmus where the gill opening extends very far forward, and may, to a certain extent, be applied to some pimelodid taxa as well. Examples are Sorubim and Pseudoplatystoma which also possess long gill openings and a high number of branchiostegal rays (11-16). 


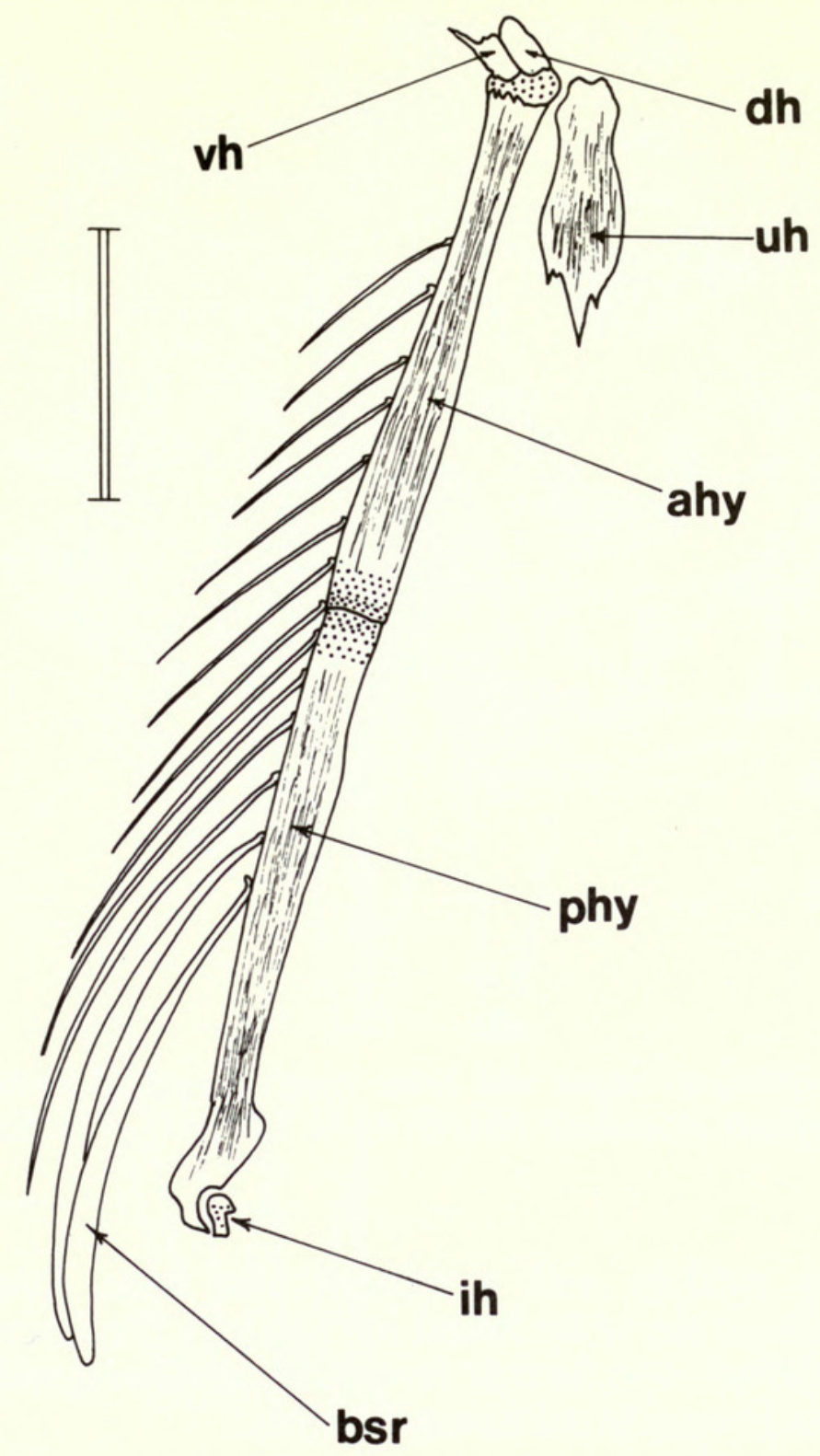

Fig. 25 Hypophthalmus edentatus hyoid arch, lateral view. Specimen BMNH 1972.7.27: 675-678. Scale $=5 \mathrm{~mm}$.

According to McAllister (1968) a high number of branchiostegal rays is the primitive condition in teleosts. On this basis he considers that amongst siluroids the Old World taxa '...appear to be more primitive than the South American catfishes, having 4-20 branchiostegals as opposed to 3-17...' The extent of these ranges and the degree of overlap hardly justify such a statement. From McAllister's counts for siluroid families, the predominant number of branchiostegal rays would seem to be 9-11 and perhaps this, by virtue of its widespread occurrence, should be thought of as the plesiomorph number rather than the high number advocated by McAllister. Further comparative data, particularly on the morphology and the placement of the branchiostegal rays on the hyoid bar are necessary before any valid statement can be made concerning the apo- or plesiomorphy of their number.

The relationships of the interhyal to the preoperculum shows some interesting modifications in the Pimelodidae. The usual siluroid condition, as in other ostariophysans, is for the interhyal to articulate between the quadrate, or symplectic, and the hyomandibular limb. In most siluroids the interhyal attaches, in the absence of a symplectic, ligamentously to both quadrate and hyomandibula, abutting against the intervening cartilage (see description of Hypophthalmus above). In Pseudoplatystoma the interhyal has shifted posteriorly to such an extent that its connection with the hyomandibula and quadrate is lost, 


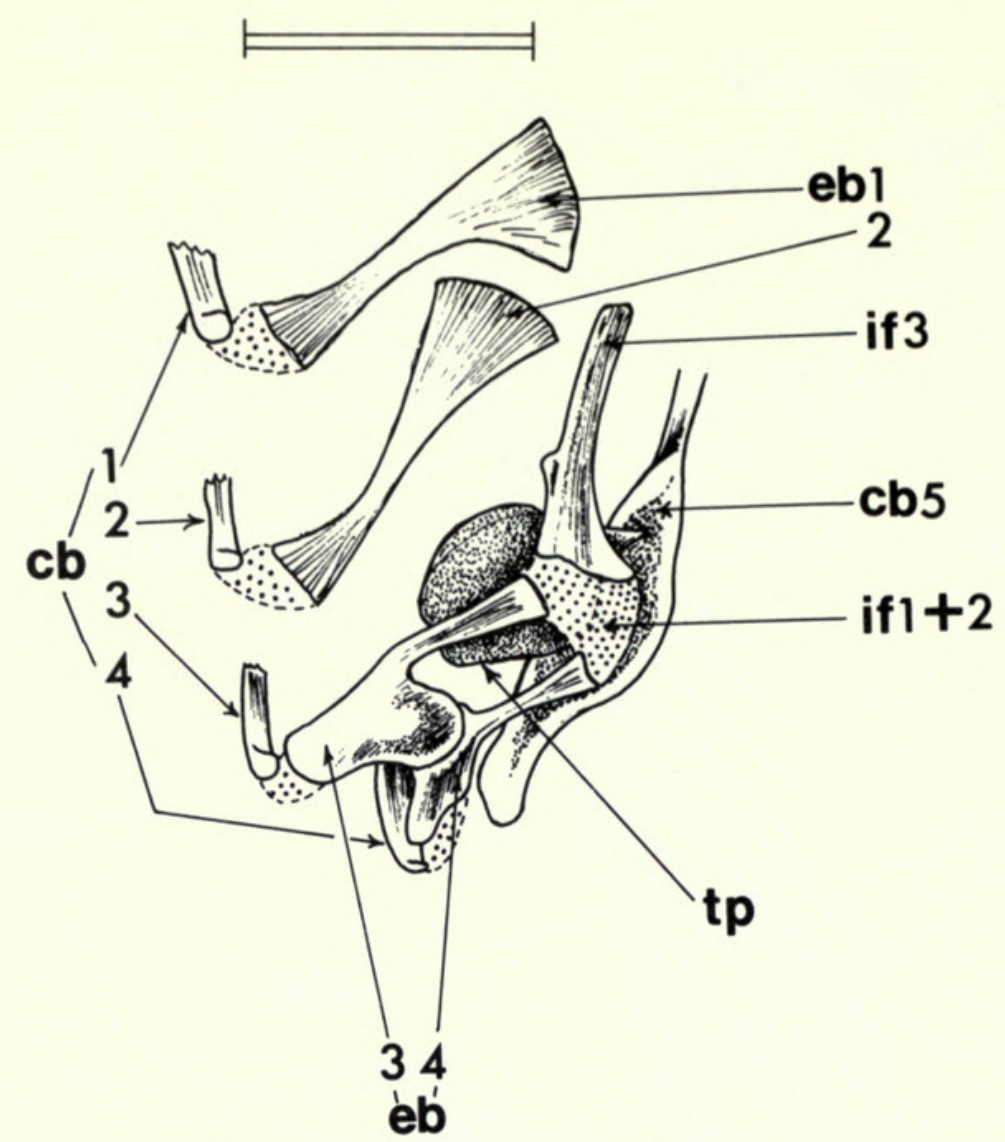

Fig. 26 Hypophthalmus edentatus upper and lower (part) branchial arches, dorsal view, left side (cartilage stippled). Specimen BMNH 1972.7.27: 675-678. Scale $=3 \mathrm{~mm}$.

and instead it articulates entirely with a preopercular fossa. Intermediate stages in the development of this condition are to be found in Goldiella, Sorubim and Brachyplatystoma where the interhyal has shifted even further posteriorly and is ligamentously attached to the rim of a preopercular fossa alongside the hyomandibula.

The opercular series (Fig. 23)

The preoperculum (po) of Hypophthalmus is a thin, narrow bone covering the posterior margins of the hyomandibula and the quadrate, virtually obscuring the interoperculum. The interoperculum (iop) is roughly triangular but with a concave ventral border where it overlaps the pectoral fin base. The operculum (op) is almost equilaterally triangular, its posterior edge much fretted, and its entire structure cancellous.

The opercular bones of Hypophthalmus appear to be of a 'generalised' siluroid type, i.e. a large operculum, almost vertical preoperculum and small interoperculum. There is considerable variability in size and shape of these elements throughout the Siluroidei (Howes, in press). Fink \& Fink (1981) maintain that the triangular shape of the operculum is synapomorphic for the siluroids and gymnotoids. However, whereas the ventro-posterior border of the operculum in siluroids is either straight or concave, that in gymnotoids is more often convex, as in other otophysans.

The gill arches (Figs 26-27)

Upper elements (Fig. 26). The epibranchials of Hypophthalmus edentatus are narrowwaisted, with expanded medial surfaces and bear 25-27 long, fine gill-rakers, As in all siluroids examined, epibranchial (eb) 3 has an uncinate process which in Hypophthalmus is rounded and overlies the central portion of eb4. Infrapharyngobranchial (if) 3 is well-ossified and elongate, its posterior margin separated from eb3 and eb4 by a cartilaginous wedge. Of the two alizarin preparations at my disposal, the larger shows two distinct chondrifications in 


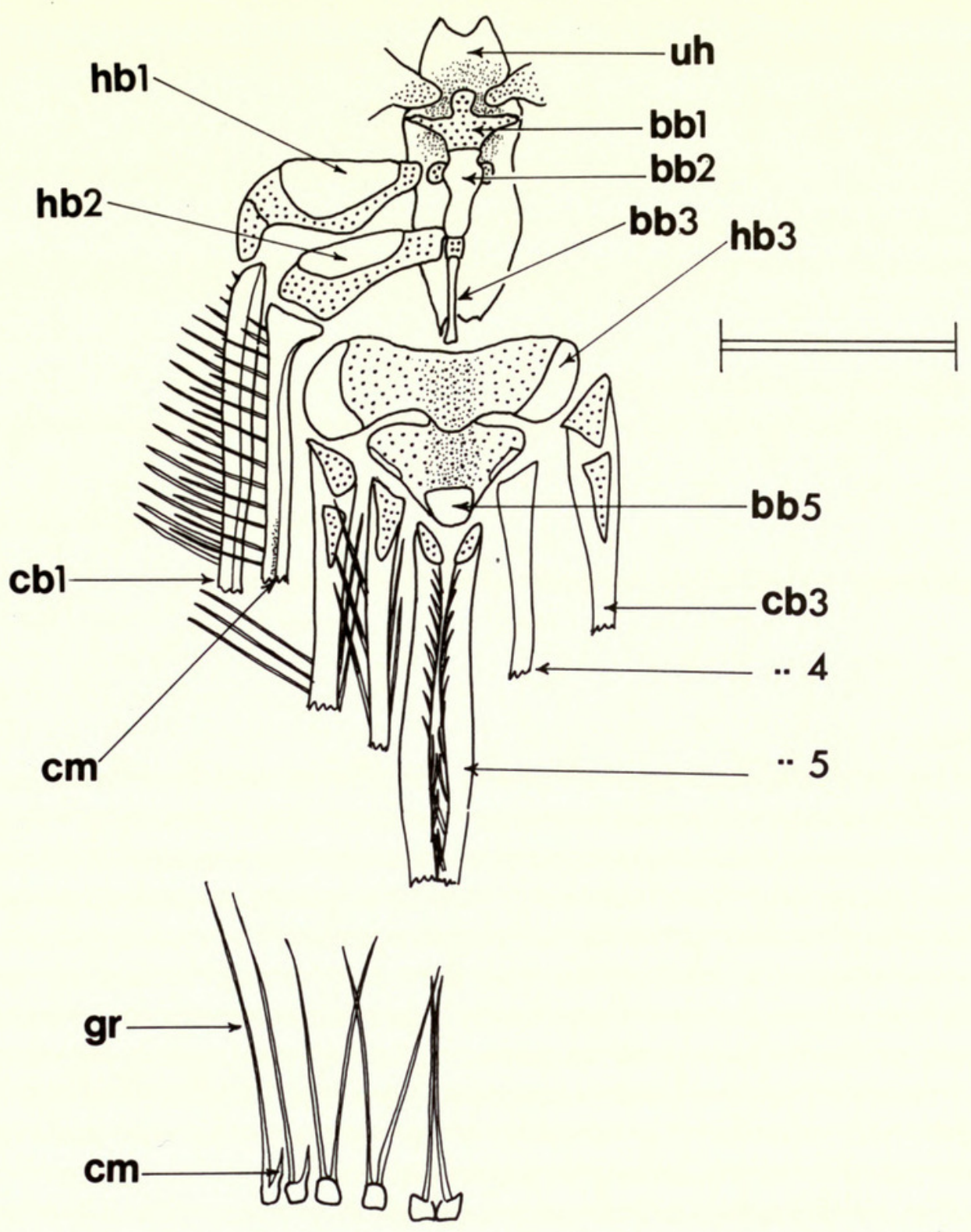

Fig. 27 Hypophthalmus edentatus lower branchial arch elements; (upper) dorsal view. Specimen BMNH 1972.7.27: 675-678. Scale $=3 \mathrm{~mm}$; (lower) cross section of left side gill-rakers and ceratobranchials. $\mathrm{cm}=$ ceratobranchial membrane.

this wedge. These cartilages suspend a large oval toothplate bearing on its ventral surface many minute, conical teeth (tp, Fig. 26).

Lower elements (Fig. 27). The basibranchials (bb) and hypobranchials (hb) are poorly ossified. Basibranchial 1 is a triangularly shaped cartilage lying in the plane of the anterohyals; basibranchials 2 and 3 are rod-like ossified elements; basibranchial 4 is incorporated within a broad cartilaginous cornua, the ossified lateral margins of which represent hypobranchials 4; basibranchial 5 is represented by a triangular cartilage whose apex is ossified. Hypobranchials 1-3 are ossified only along their leading edges.

The ceratobranchials are the most elongate of any siluroid and carry at least 200 long gill-rakers. The first two ceratobranchials (cb) have only a single row of gill-rakers (gr), along the outer edge; the inner edge has a low wall of fibrous connective tissue $(\mathrm{cm})$. The other ceratobranchials have a double row of gill-rakers; the 5th is dentigerous, its anterior stem is excessively elongate and meets its fellow along the midline. The gill-rakers on cb 5 occur only along the inner margin; anteriorly the rakers of each ceratobranchial intermesh.

Roberts (1972) described the sieving mechanism of the gill-rakers. The arrangement of this mechanism is shown in Fig. 27 as a transverse section of the lower gill-arch. Such an arrangement does not occur in any other siluroid. 


\section{Postcranial elements}

As this study is concerned primarily with the cranial anatomy of Hypophthalmus, no detailed description of the postcranial anatomy is presented. The following features, however, are worthy of note.

The pectoral girdle is of simple construction, with a greatly elongated horizontal cleithral limb and the coracoid reduced to a horizontal lamina. Such elongation of the cleithrum is unknown in any other siluroid.

There are 62 vertebrae, excluding the complex vertebrae. This is an exceptionally high number amongst siluroids and is exceeded only by members of the Clariidae. Virtually no comparative data exist for vertebral numbers in siluroids. A superficial survey indicates that the mean siluroid count is 40-45. High counts are found among Ariidae 49-50, Ageneiosidae 49-50, Siluridae 50-51 and Clariidae 60+. Among the Pimelodidae only Luciopimelodus has an exceptionally high count $47-48$.

The caudal fin skeleton of Hypophthalmus is of a plesiomorph pattern with no fusion of any hypural elements (PH;1;2;3;4;5). Lundberg \& Baskin (1969) found hypural fusion and reduction of principal caudal fin rays to be widespread conditions. The most derived hypural fusion patterns occur in the Plotosidae, Chacidae and Loricariidae. In the latter family there is also an expansion of the last neural spine, which contacts the upper caudal element, i.e. the fused hypurals 3-5, uroneural and epural. Certainly the derived caudal fusion patterns shared by the Loricariidae, Callichthyidae and Astroblepidae are congruent with synapomorphies involving the encapsulation of the swimbladder (see p. 27).

Other caudal fin patterns are not so easy to interpret and characters such as the absence of an hypurapophysis in the Clariidae and Plotosidae are interpreted as parallelisms by Lundberg \& Baskin. Although both clariids and plotosiids trend toward anguilliform morphology, it is interesting to note that the hypural fusion pattern in clariids (excluding the Heteropneustidae) is, in contrast to plotosiids, plesiomorph. Even in such a seemingly derived taxon as Allabenchelys all the hypurals are free.

Amongst the Pimelodidae, the predominant caudal fusion pattern is a free parhypural; $1+2 ; 3+4 ; 5$, which as Lundberg \& Baskin (1969:40) remark is significantly more advanced than that of any bagrid. The hypural fusion patterns yield little support for the proposed groupings of pimelodids presented below, except that Rhamdia and Pimelodella share a similar fusion of hypurals, $1+2$ and $3+4$.

\section{Relationships of the Hypophthalmidae}

Anatomically, the Hypophthalmidae is a unique group. No other siluroid has such an arrangement of the eye musculature, hypertrophy of the jaw adductor muscles, reduction of ethmoidal ossification, complexly developed mandibular barbel supporting elements, elongated gill- and hyoid arch elements, and profoundly modified vertebral and swimbladder elements.

Attention was drawn in the Introduction to the poverty of published data on siluroid comparative anatomy. In order to apply cladistic methods in resolving interrelationships extensive comparisons must be made thus, at this stage one cannot, with any degree of certainty identify plesiomorph or apomorph characters amongst siluroids. However, from this survey it is clear that the sister-group to the Hypophthalmidae lies within the Pimelodidae. Synapomorphies are manifest in the structure of the ethmoid region, the mandibular barbel articulation, the eye muscle arrangement, the complex vertebrae, and the sensory canal system. The following is a synopsis of these characters:

1. Ethmoid region with lateral cavity (p. 20)—shared with Luciopimelodus, Pinirampus and Pimelodus (part).

2. Articulation of the mandibular barbels with large cartilaginous plates (p. 21)-shared with Luciopimelodus, Iheringichthys, Sorubim, Pinirampus, Pseudoplatystoma, Pimelodus (part). 
3. Anterior eye musculature of tendinous origin—shared with Sorubimichthys

4. Network of epidermal canals crossing the orbital and opercular regions-shared with Luciopimelodus and Iheringichthys.

5. Posterior extension of the 'posttemporal' passing beyond the edge of the Müllerian ramus, elevation of that ramus, and vertical path of the anterior portion of the vaugus lateralis nerve-shared with Luciopimelodus.

In the course of this study only a limited number of pimelodid taxa was studied, but even this preliminary investigation reveals that there are at least three major groups contained within the Pimelodidae as presently recognised, viz:

1. Those species with the swimbladder partially encapsuled and usually with a caecal posterior border; the 5th and 6th fused within the vertebral complex; the ventral superficial ossification of the 4th and 5th centra forming a tunnel for the dorsal aorta; absence of a retractor tentaculi muscle.

Included taxa: Iheringichthys, Pinirampus, Callophysus, Parapimelodus, Pimelodina, Perugia, Megalonema, Luciopimelodus, Pimelodus (part). In addition, the first four genera and Pimelodus maculatus all have a scythe-shaped pterygoid bone lying anterior to the main pterygoid series and attaching to the lateral ethmoid via a ligament (p. 31).

2. Those species with the swimbladder well-developed, not encapsuled, and with attached muscles (see below); 6 vertebrae forming the anterior complex centrum, the 4th and 5th centra elongate and forming an aortic tunnel. A retractor tentaculi muscle present.

Included taxa: Pseudoplatystoma, Sorubim, Hemisorubim, Pimelodus (part).

The distribution of swimbladder muscles throughout the Pimelodidae as a whole has still to be recorded. Bridge \& Haddon (1894) described swimbladder compressor muscles in Pseudoplatystoma, (their Platystoma) as originating from the occiput and inserting on the antero-ventral wall of the swimbladder. These authors also described a tensor tripodis muscle in Pseudoplatystoma and some other pimelodontid taxa. This muscle runs from the exoccipital and inserts tendinously into the anterior wall of the swimbladder.

Alexander (1965: 110) was unable to trace the tensor tripodis in Pimelodus blochii, Alexander's $P$. clarias. However, it appears in this species as a mere strip of tendinous fibres. The muscle is also present in Sorubim and Hemisorubim

3. Those species with the swimbladder well-developed, not encapsuled, and without compressor muscles; 5 fused centra, sometimes with superficial ossification but without an aortic tunnel. The lateral ethmoid is transversly convex.

Included taxa: Rhamdia, Pimelodella, Heptapterus

The above groups include taxa presently distributed amongst four subfamilies, the Pimelodinae, Luciopimelodinae, Callophysinae and Sorubiminae. None of the three groups defined here corresponds with any subfamily as presently recognised. In addition, there is another subfamily, the Pseudopimelodinae (Gomes, 1946). Representatives of this latter group have not been thoroughly investigated in the course of this study, but in those that have been examined the anterior part, at least, of the swimbladder is divided by an extension of the complex vertebrae.

No meaningful phylogenetic classification is accomplished in recognising the above named pimelodid subfamilies, based as they are on a mixture of plesio- and apomorphies. Similarly, placing the Hypophthalmidae in a separate suborder (Chardon, 1968) simply to recognise its morphological distinctiveness, serves no purpose in elucidating its relationships.

From the characters analysed above synapomorphies have been identified that indicate the sister group of the Hypophthalmidae to be in that assemblage which includes Luciopimelodus and Iheringichthys. A more refined definition of this group must await a thorough anatomical study of the Pimelodidae. 


\section{Acknowledgements}

This paper has benefited greatly from the critical and constructive comments of Drs Humphry Greenwood, Keith Banister and Paul Skelton, to all of whom I extend my sincere thanks.

I particularly thank Bernice Brewster, Lynne Parenti, Chris Sanford and Rob Travers for so much helpful advice and technical assistance.

I am deeply indebted to those many ichthyological colleagues and associates who, over the years, have provided specimens and given me so freely and patiently much information on catfishes.

\section{References}

Alexander, R. McN. 1964. The structure of the Weberian apparatus in the Siluri. Proc. zool. Soc. Lond. 142: 419-440. 1965. Structure and function in catfish. J. Zool. Lond., 148: 88-152.

Allis, E. P. 1908. The pseudobranchial and carotid arteries in Ameiurus. Anat. Anz. 33: 256-270.

The myodome and trigemino-facialis chamber of fishes, and the corresponding cavities in higher vertebrates. J. Morph. 32: 207-322.

Bamford, T. W. 1948. Cranial development of Galeichthys felis Proc. Zool. Soc. Lond. 118 (2): 364-391.

Beer, G. R. de, 1937. The development of the vertebrate skull Oxford. 552pp.

Bridge, T. W. \& Haddon, A. C. 1894. Contributions to the anatomy of fishes II. The air-bladder and Weberian ossicles in the siluroid fishes. Phil. Trans. Roy. Soc. B, 184: 65-333.

Carvalho, F. M. 1980 a Composição química e reproduçáo do mapará (Hypophthalmus edentatus Spix, 1829) do lago do Castanho, Amazonas. Acta Amazonica 10 (2): 379-389.

— 1980 b Alimentaçáo do mapará (Hypophthalmus edentatus Spix, 1829) do lago do Castanho, Amazonas (Siluriformes, Hypophthalmidae). Acta Amazonica 10 (3): 545-555.

Chardon, M. 1968. Anatomie comparée de l'appareil de Weber et des structures connexes chez les Siluriformes. Ann. Mus. roy. Afr. ser. 8 Zool. 169: 1-277.

Cope, E. D. 1871. Observations on the systematic relations of the fishes. Proc. Amer. Ass. Adv. Sci. 20: 317-343.

Daget, J. 1964. Le crâne des téléostéens. Mem. Mus. natn. Hist. nat. Paris (A) 31: 163-341.

Dullemeijer, P. \& Barel, C. D. N. 1977. Functional morphology and evolution. In: Major Patterns in Vertebrate Evolution Hecht, M. K., Goody, P. C. \& Hecht, B. M. (Eds): 83-117. New York.

Eaton, T. H. 1948. Form and function in the head of the channel catfish, Ictalurus lacustris punctatus. J. Morph. 83: 181-194.

Edgeworth, F. H. 1935. The cranial muscles of the Vertebrates. Cambridge.

Eigenmann, C. H. \& Eigenmann, R. S. 1890. A revision of the South American nematognathi, or catfishes. Occ. Pap. Calif. Acad. Sci. 1: 1-508.

Fink, S. V. \& Fink, W. L. 1981. Interrelationships of the ostariophysan fishes (Teleostei). Zool. J. Linn. Soc. 72(4): 297-353.

Gee, J. H. 1976. Buoyancy and aerial respiration: factors influencing the evolution of reduced swimbladder volume of some Central American catfishes (Trichomycteridae, Callichthyidae, Loricariidae, Astrobelpidae). Can. J. Zool. 54 (7): 1030-1037.

Gelinek, E. 1978. On the ampullary organs of the South-American paddle-fish Sorubim lima (Siluroidea, Pimelodidae). Cell Tiss. Res. 190: 357-369.

Ghiot, F. 1978. The barbel movements of three South American pimelodid catfishes. Zool. Anz. 200 (5-6): $395-401$.

Gomes, A. L. 1946. A review of Microglanis, a genus of South American catfishes with notes on related genera. Occ. Pap. Mus. Zool. Univ. Mich. 494: 1-19.

Goodrich, E. S. 1930. Studies on the structure and development of vertebrates. Reprint edit. New York (1958).

Gosline, W. A. 1973. Considerations regarding the phylogeny of cypriniform fishes, with special reference to structures associated with feeding. Copeia 1973 (4): 761-776.

- 1975. The palatine-maxillary mechanism in catfishes, with comments on the evolution and zoogeography of modern siluroids. Occ. Pap. Calif. Acad. Sci. (120): 1-31.

Goulding, M. 1980. The Fishes and the Forest. Berkeley, Los Angeles and London. 
Greenwood, P. H., Rosen, D. E., Weitzman, S. H. \& Myers, G. S. 1966. Phyletic studies of teleostean fishes with a provisional classification of living forms. Bull. Am. Mus. nat. Hist. 131: 339-456.

Günther, A. 1864. Catalogue of fishes in the British Museum 5. London. 455pp.

Howes, G. J. 1980. A new catfish from Sierra Leone. Bull. Br. Mus. nat. Hist (Zool.) 38 (3): 165-170.

- in press. The cranial muscles of loricariid fishes, their homologies and use as phylogenetic characters. Bull. Br. Mus. nat. Hist. (Zool.)

Juge, M. 1899. Recherches sur le nerfe cérébraux et la musculature céphalique de Silurus glanis. Rev. Suisse Zool. 6: 1-171.

Kesteven, H. L. 1943. The evolution of the skull and cephalic muscles. The fishes. Pt. 1. Mem. Australian Mus. 8 (2): 63-132.

Kindred, J. E. 1919. The skull of Amiurus. Illinois biol. Monogr. 5 (1): 1-120.

Lubosch, W. 1938. Muskeln des Kopfes: Viscerale Muskulatur (Fortsetzung). B. Teleostier. In: Handbuch der vergleichenden Anatomie der Wirbeltiere. Bolk, L., Goppert, E., Kallius, E. \& Lubosch, W. (Eds) 5: 1011-1024. Berlin \& Vienna.

Lundberg, J. G. 1975. Homologies of the upper shoulder girdle and temporal region bones in catfishes (order Siluriformes), with comments on the skull of the Helogeneidae. Copeia 1975 (1): 66-74.

McAllister, D. E. 1968. The evolution of branchiostegals and associated opercular, gular and hyoid bones and the classification of teleostome fishes, living and fossil. Bull. natn. Mus. Can. (Biol.) 77 (221): 1-239.

McMurrich, J. P. 1884a. The osteology of Amiurus catus (L.) Gill. Proc. Can. Inst. 2: 270-310.

$1844 b$ The myology of Amiurus catus (L.) Gill. Proc. Can. Inst. 2: 311-351.

Meschkat, A. 1960. Report to the Government of Brazil on the fisheries of Amazon region. BRA/TE/FI Rept. No. 1305. FAO, Rome.

Mithel, M. 1964. The cranial nerves of Mystus seenghala (Sykes) Agra Univ. J. Res. 13: 67-78.

Muller, J. 1842. Beobachtungen über die Schwimblase der Fische, mit Bezug auf einige neue Fischgattungen. Arch. Anat. Physiol.: 307-329.

Nelson, E. M. 1960. The morphological relationships of the lateral-line nerve in certain 'Electric Fishes'. Copeia 1960 (2): 130-134.

Qasin, S. Z. \& Hasan, R. 1961. A hydrostatic function of the accessory respiratory organs in air breathing fishes. Nature 191, 396-7.

Regan, C. T. 1911. Classification of the teleostean fishes of the order Ostariophysi, Siluroidea. Ann. Mag. nat. Hist. 8, (8): 553-577.

Roberts, T. R. 1972. Ecology of fishes in the Amazon and Congo basins. Bull. Mus. Comp. Zool. 143 (2): 117-147.

- 1973. Interrelationships of ostariophysans. In: Interrelationships of fishes. Greenwood, P. H., Miles, R. S. \& Patterson, C. (Eds) 373-395 London \& New York.

Rosen, D. E. 1964. The relationships and taxonomic position of the halfbeaks, killifishes, silversides and their relatives. Bull. Am. Mus. nat. Hist. 127 (5): 219-267.

Singh, B. R. 1967. Movements of the barbels in some siluroid fishes. Zool. Anz. 178 (5-6): 402-412.

Szabo, T. 1974. Anatomy of the specialized lateral line organs of electroreception. In: Electroreceptors and other specialized receptors in lower vertebrates. Fessard, A. (Ed.) 13-58. Berlin.

Takahasi, N. 1925. On the homology of the cranial muscles of the cypriniform fishes. J. Morph. 40: 1-109.

Tavolga, W. N. 1962. Mechanisms of sound production in the ariid catfishes Galeichthys and Bagre. Bull. Amer. Mus. nat. Hist. 124 (3): 5-30.

Tilak, R. 1965. The comparative morphology of the osteocranium and Weberian apparatus of Tachysuridae (Pisces, Siluroidei). J. Zool. 146 (2): 150-174.

Vari, R. P. 1979. Anatomy, relationships and classification of the families Citharinidae and Distichodontidae (Pisces, Characoidea). Bull. Br. Mus. nat. Hist. (Zool.) 36(5): 261-344.

Winterbottom, R. 1974. A descriptive synonymy of the striated muscles of the teleostei. Proc. Acad. nat. Sci. Philad. 125: 225-317.

Wright, R. Ramsay 1885. On the skull and auditory organ of the siluroid Hypophthalmus. Trans Roy. Soc. Canada. Sect. IV: 107-117. 


\section{$2 \mathrm{BHL}$ Biodiversity Heritage Library}

1983. "Problems in catfish anatomyand phylogeny as exemplified by theNeotropical Hypopthalmidae (Teleostei: Siluroidei)." Bulletin of the British Museum (Natural History) Zoology 45, 1-39.

https://doi.org/10.5962/bhl.part.27994.

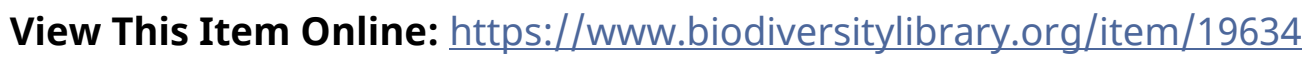

DOI: https://doi.org/10.5962/bhl.part.27994

Permalink: https://www.biodiversitylibrary.org/partpdf/27994

\section{Holding Institution}

Natural History Museum Library, London

\section{Sponsored by}

Natural History Museum Library, London

\section{Copyright \& Reuse}

Copyright Status: In copyright. Digitized with the permission of the rights holder.

Rights Holder: The Trustees of the Natural History Museum, London

License: http://creativecommons.org/licenses/by-nc-sa/4.0/

Rights: http://biodiversitylibrary.org/permissions

This document was created from content at the Biodiversity Heritage Library, the world's largest open access digital library for biodiversity literature and archives. Visit BHL at https://www.biodiversitylibrary.org. 